\title{
On Interval-Valued Hesitant Fuzzy Soft Sets
}

\author{
Haidong Zhang, ${ }^{1}$ Lianglin Xiong, ${ }^{2}$ and Weiyuan $\mathrm{Ma}^{1}$ \\ ${ }^{1}$ School of Mathematics and Computer Science, Northwest University for Nationalities, Lanzhou, Gansu 730030, China \\ ${ }^{2}$ School of Mathematics and Computer Science, Yunnan Minzu University, Kunming, Yunnan 650500, China \\ Correspondence should be addressed to Haidong Zhang; lingdianstar@163.com and Lianglin Xiong; lianglin_5318@126.com
}

Received 16 October 2014; Revised 13 January 2015; Accepted 19 January 2015

Academic Editor: Shuming Wang

Copyright (C) 2015 Haidong Zhang et al. This is an open access article distributed under the Creative Commons Attribution License, which permits unrestricted use, distribution, and reproduction in any medium, provided the original work is properly cited.

\begin{abstract}
By combining the interval-valued hesitant fuzzy set and soft set models, the purpose of this paper is to introduce the concept of interval-valued hesitant fuzzy soft sets. Further, some operations on the interval-valued hesitant fuzzy soft sets are investigated, such as complement, "AND," "OR," ring sum, and ring product operations. Then, by means of reduct interval-valued fuzzy soft sets and level hesitant fuzzy soft sets, we present an adjustable approach to interval-valued hesitant fuzzy soft sets based on decision making and some numerical examples are provided to illustrate the developed approach. Finally, the weighted interval-valued hesitant fuzzy soft set is also introduced and its application in decision making problem is shown.
\end{abstract}

\section{Introduction}

Soft sets, initiated by Molodtsov [1], are a new mathematical tool for dealing with uncertainties which are free from many difficulties that have troubled the usual theoretical approaches. It has been found that fuzzy sets, rough sets, and soft sets are closely related concepts [2]. Soft set theory has potential applications in many different fields including the smoothness of functions, game theory, operational research, Perron integration, probability theory, and measurement theory $[1,3]$.

Research works on soft sets develop very rapidly and now are one of hotspots in the uncertainty research. For example, Maji et al. [4] defined several operations on soft sets and made a theoretical study on the theory of soft sets. Jun [5] introduced the concept of soft BCK/BCI-algebras. Subsequently, they also discussed the applications of soft sets in ideal theory of BCK/BCI-algebras [6]. Feng et al. [7] applied soft set theory to the study of semirings and initiated the notion of soft semirings. Furthermore, based on [4], Ali et al. [8] introduced some new operations on soft sets and improved the notion of complement of soft set. They proved that certain De-Morgan's laws hold in soft set theory. Qin and Hong [9] introduced the concept of soft equality and established lattice structures and soft quotient algebras of soft sets. Meanwhile, the study of hybrid models combining soft sets with other mathematical structures is also emerging as an active research topic of soft set theory. Yang et al. [10] introduced the interval-valued fuzzy soft sets by combining interval-valued fuzzy set with soft set models and analyzed a decision problem by the model. By using the multifuzzy set and soft set models, Yang et al. [11] presented the concept of the multifuzzy soft sets and provided its application in decision making under an imprecise environment. Maji et al. [12] initiated the study on hybrid structures involving fuzzy sets and soft sets. They introduced the notion of fuzzy soft sets, which can be seen as a fuzzy generalization of soft sets. Furthermore, based on [12], Roy and Maji [13] presented a novel method concerning object recognition from an imprecise multiobserver data so as to cope with decision making based on fuzzy soft sets. Then Kong et al. [14] revised the Roy-Maji method by considering "fuzzy choice values." Subsequently, Feng et al. [15, 16] further discussed the application of fuzzy soft sets and interval-valued fuzzy soft sets to decision making in an imprecise environment. They proposed an adjustable approach to fuzzy soft sets and interval-valued fuzzy soft sets based decision making in $[15,16]$. By introducing the interval-valued intuitionistic fuzzy sets into soft sets, Jiang et al. [17] defined the concept of interval-valued intuitionistic fuzzy soft set. Moreover, they also defined some operations on the interval-valued intuitionistic fuzzy soft sets and investigated some basic properties. On the basis of [17], Zhang et al. [18] developed 
an adjustable approach to decision making problems based on interval-valued intuitionistic fuzzy soft sets. Very recently, integrating trapezoidal fuzzy sets with soft sets, Xiao et al. [19] initiated the trapezoidal fuzzy soft sets to deal with certain linguistic assessments. Further, in order to capture the vagueness of the attribute with linguistic assessments information, Zhang et al. [20] generalized trapezoidal fuzzy soft sets introduced by Xiao et al. [19] and defined the concept of generalized trapezoidal fuzzy soft sets.

As a mathematical method to deal with vagueness in everyday life, fuzzy set was introduced by Zadeh in [21]. Up to present, several extensions have been developed, such as intuitionistic fuzzy set [22], interval valued fuzzy sets [23$25]$, type-2 fuzzy set [26, 27], and type- $n$ fuzzy set [26]. Recently, Torra and Narukawa $[28,29]$ extended fuzzy sets to hesitant fuzzy environment and initiated the notion of hesitant fuzzy sets (HFSs), because they found that because of the doubts between a few different values, it is very difficult to determine the membership of an element to a set under a group setting [29]. For example, two decision makers discuss the membership degree of $x$ into $A$. One wants to assign 0.7 , but the other wants to assign 0.9. They cannot persuade each other. To avoid an argument, the membership degrees of $x$ into $A$ can be described as $\{0.7,0.9\}$. After it was introduced by Torra, the hesitant fuzzy set has attracted more and more scholars' attention [30-32].

As mentioned above, there are close relationships among the uncertainty theories, such as fuzzy sets, rough sets, and soft sets. So many hybrid models among them are proposed by the researchers, such as fuzzy rough sets [33], rough fuzzy sets [33], and fuzzy soft sets [12]. Since the appearance of hesitant fuzzy set, the study on it has never been stopped. The combination of hesitant fuzzy set with other uncertainty theories is a hot spot of the current research recently. There are several hybrid models in present, such as hesitant fuzzy rough sets [34] and hesitant fuzzy soft sets [35, 36]. In fact, Babitha and John [35] defined a hybrid model called hesitant fuzzy soft sets and investigated some of their basic properties. Meanwhile, Wang et al. [36] also initiated the concept of hesitant fuzzy soft sets by integrating hesitant fuzzy set with soft set model and presented an algorithm to solve decision making problems based on hesitant fuzzy soft sets. By combining hesitant fuzzy set and rough set models, Yang et al. [34] introduced the concept of the hesitant fuzzy rough sets and proposed an axiomatic approach to the model.

However, Chen et al. $[37,38]$ pointed out that it is very difficult for decision makers to exactly quantify their ideas by using several crisp numbers because of the lack of available information in many decision making events. Therefore, Chen et al. $[37,38]$ extended hesitant fuzzy sets into intervalvalued hesitant fuzzy environment and introduced the concept of interval-valued hesitant fuzzy sets (IVHFSs), which permits the membership degrees of an element to a given set to have a few different interval values. It should be noted that when the upper and lower limits of the interval values are identical, IVHFS degenerates into HFS, indicating that the latter is a special case of the former. Recently, similarity, distance, and entropy measures for IVHFSs have been investigated by Farhadinia [39]. Wei et al. [40] discussed some interval-valued hesitant fuzzy aggregation operators and gave their applications to multiple attribute decision making based on interval-valued hesitant fuzzy sets.

As a novel mathematical method to handle imprecise information, the study of hybrid models combining IVHFSs with other uncertainty theories is emerging as an active research topic of IVHFS theory. Meanwhile, we know that there are close relationships among the uncertainty theories, such as interval-valued hesitant fuzzy sets, rough sets, and soft sets. Therefore, many scholars have been starting to research on the area. For example, Zhang et al. [41] generalized the hesitant fuzzy rough sets to interval-valued hesitant fuzzy environment and presented an interval-valued hesitant fuzzy rough set model by integrating interval-valued hesitant fuzzy set with rough set theory. On the one hand, it is unreasonable to use hesitant fuzzy soft sets to handle some decision making problems because of insufficiency in available information. Instead, adopting several interval numbers may overcome the difficulty. In that case, it is necessary to extend hesitant fuzzy soft sets [36] into interval-valued hesitant fuzzy environment. On the other hand, by referring to a great deal of literature and expertise, we find that the discussions about fusions of interval-valued hesitant fuzzy set and soft sets do not also exist in the related literatures. Considering the above facts, it is necessary for us to investigate the combination of IVHFS and soft set. The purpose of this paper is to initiate the concept of interval-valued hesitant fuzzy soft set by combining interval-valued hesitant fuzzy set and soft set theory. In order to illustrate the efficiency of the model, an adjustable approach to interval-valued hesitant fuzzy soft sets based on decision making is also presented. Finally, some numerical examples are provided to illustrate the adjustable approach.

To facilitate our discussion, we first review some backgrounds on soft sets, fuzzy soft sets, hesitant fuzzy sets, and interval numbers in Section 2. In Section 3, the concept of interval-valued hesitant fuzzy soft set with its operation rules is presented. In Section 4, an adjustable approach to intervalvalued hesitant fuzzy soft sets based on decision making is proposed. In Section 5, the concept of weighted intervalvalued hesitant fuzzy soft sets is defined and applied to decision making problems in which all the decision criteria may not be of equal importance. Finally, we conclude the paper with a summary and outlook for further research in Section 6.

\section{Preliminaries}

In this section, we briefly review the concepts of soft sets, fuzzy soft sets, hesitant fuzzy sets, and interval numbers. The pair $(U, E)$ will be called a soft universe. Throughout this paper, unless otherwise stated, $U$ refers to an initial universe, $E$ is a set of parameters, $P(U)$ is the power set of $U$, and $A \subseteq E$.

2.1. Soft Sets, Fuzzy Soft Sets, and Hesitant Fuzzy Sets. According to [1], the concept of soft sets is defined as follows.

Definition 1 (see [1]). A pair $(F, A)$ is called a soft set over $U$, where $F$ is a mapping given by $F: A \rightarrow P(U)$. 
Combining fuzzy sets and soft sets, Maji et al. [12] initiated the following hybrid model called fuzzy soft sets, which can be seen as an extension of both fuzzy sets and crisp soft sets.

Definition 2 (see [12]). A pair $(F, A)$ is called a fuzzy soft set over $U$ if $A \subseteq E$ and $F: A \rightarrow F(U)$, where $F(U)$ is the set of all fuzzy subsets of $U$.

In the following, we review some basic concepts related to hesitant fuzzy sets introduced by Torra [28, 29].

Definition 3 (see $[28,29]$ ). Let $X$ be a fixed set; a hesitant fuzzy set (HFS, for short) $\widehat{A}$ on $X$ is in terms of a function $h_{\widehat{A}}(x)$ that when applied to $X$ returns a subset of $[0,1]$; that is,

$$
\widehat{A}=\left\{\left\langle x, h_{\widehat{A}}(x)\right\rangle \mid x \in X\right\},
$$

where $h_{\widehat{A}}(x)$ is a set of some different values in $[0,1]$, representing the possible membership degrees of the element $x \in X$ to $\widehat{A}$.

For convenience, we call $h_{\widehat{A}}(x)$ a hesitant fuzzy element (HFE, for short).

Example 4. Let $X=\left\{x_{1}, x_{2}, x_{3}\right\}$ be a reference set and let $h_{\widehat{A}}\left(x_{1}\right)=\{0.7,0.4,0.5\}, h_{\widehat{A}}\left(x_{2}\right)=\{0.2,0.4\}$, and $h_{\widehat{A}}\left(x_{3}\right)=$ $\{0.3,0.1,0.7,0.6\}$ be the HFEs of $x_{i}(i=1,2,3)$ to a set $\widehat{A}$, respectively. Then $\widehat{A}$ can be considered as a HFS; that is,

$$
\begin{gathered}
\widehat{A}=\left\{\left\langle x_{1},\{0.7,0.4,0.5\}\right\rangle,\left\langle x_{2},\{0.2,0.4\}\right\rangle,\right. \\
\left.\left\langle x_{3},\{0.3,0.1,0.7,0.6\}\right\rangle\right\} .
\end{gathered}
$$

2.2. Interval Numbers. In [42], $\mathrm{Xu}$ and $\mathrm{Da}$ gave the concept of interval numbers and further investigated some of their properties.

Definition 5 (see [42]). Let $a=\left[a^{L}, a^{U}\right]=\left\{x \mid a^{L} \leq x \leq a^{U}\right\}$; then $a$ is called an interval number. In particular, $a$ is a real number, if $a^{L}=a^{U}$.

Definition 6 (see [42]). Let $a=\left[a^{L}, a^{U}\right], b=\left[b^{L}, b^{U}\right]$, and $\lambda \geq 0$; then one has the following:

(1) $a=b$, if $a^{L}=b^{L}$ and $a^{U}=b^{U}$,

(2) $a+b=\left[a^{L}+b^{L}, a^{U}+b^{U}\right]$,

(3) $\lambda a=\left[\lambda a^{L}, \lambda a^{U}\right]$. In particular, $\lambda a=0$, if $\lambda=0$.

Definition 7 (see [42]). Let $a=\left[a^{L}, a^{U}\right]$, and $b=\left[b^{L}, b^{U}\right]$, and let $l_{a}=a^{U}-a^{L}$ and $l_{b}=b^{U}-b^{L}$; then the degree of possibility of $a \geq b$ is defined as

$$
p(a \geq b)=\max \left\{1-\max \left(\frac{b^{U}-a^{L}}{l_{a}+l_{b}}, 0\right), 0\right\} .
$$

Similarly, the degree of possibility of $b \geq a$ is defined as

$$
p(b \geq a)=\max \left\{1-\max \left(\frac{a^{U}-b^{L}}{l_{a}+l_{b}}, 0\right), 0\right\} .
$$

Equations (3) and (4) are proposed in order to compare two interval numbers and to rank all the input arguments. Further details could be found in [42].

\section{Interval-Valued Hesitant Fuzzy Soft Sets}

3.1. Concept of Interval-Valued Hesitant Fuzzy Sets. In the subsection, we review some basic concepts related to intervalvalued hesitant fuzzy sets introduced by Chen et al. [37].

Definition 8 (see [37]). Let $X$ be a fixed set, and let $\operatorname{Int}[0,1]$ be the set of all closed subintervals of $[0,1]$. An interval-valued hesitant fuzzy set (IVHFS, for short) $\widetilde{A}$ on $X$ is defined as

$$
\widetilde{A}=\left\{\left\langle x, h_{\widetilde{A}}(x)\right\rangle \mid x \in X\right\},
$$

where $h_{\widetilde{A}}(x): X \rightarrow \operatorname{Int}[0,1]$ denotes all possible intervalvalued membership degrees of the element $x \in X$ to $\widetilde{A}$.

For convenience, we call $h_{\widetilde{A}}(x)$ an interval-valued hesitant fuzzy element (IVHFE, for short). The set of all intervalvalued hesitant fuzzy sets on $U$ is denoted by $\operatorname{IVHF}(U)$. From Definition 8 , we can note that an IVHFS $\widetilde{A}$ can be seen as an interval-valued fuzzy set if there is only one element in $h_{\widetilde{A}}(x)$, which indicates that interval-valued fuzzy sets are a special type of IVHFSs.

Example 9. Let $X=\left\{x_{1}, x_{2}\right\}$ be a reference set, and let $h_{\widetilde{A}}\left(x_{1}\right)=\{[0.2,0.3],[0.4,0.6],[0.5,0.6]\}$ and $h_{\widetilde{A}}\left(x_{2}\right)=\{[0.3$, $0.5],[0.4,0.7]\}$ be the IVHFEs of $x_{i}(i=1,2,3)$ to a set $\widetilde{A}$, respectively. Then $\widetilde{A}$ can be considered as an IVHFS; that is,

$$
\begin{gathered}
\widetilde{A}=\left\{\left\langle x_{1},\{[0.2,0.3],[0.4,0.6],[0.5,0.6]\}\right\rangle,\right. \\
\left.\left\langle x_{2},\{[0.3,0.5],[0.4,0.7]\}\right\rangle\right\} .
\end{gathered}
$$

It is noted that the number of interval values in different IVHFEs may be different and the interval values are usually out of order. Suppose that $l(h)$ stands for the number of interval values in the IVHFE $h$. To operate correctly, Chen et al. [37] gave the following assumptions.

(A1) All the elements in each IVHFE $h$ are arranged in increasing order by (3). Let $h^{\sigma(k)}$ stand for the $k$ th largest interval numbers in the IVHFE $h$, where

$$
h^{\sigma(k)}=\left[h^{\sigma(k) L}, h^{\sigma(k) U}\right]
$$

is an interval number, and $h^{\sigma(k) L}=\inf h^{\sigma(k)}, h^{\sigma(k) U}=$ $\sup h^{\sigma(k)}$ represent the lower and upper limits of $h^{\sigma(k)}$, respectively.

(A2) If two IVHFEs $h_{1}, h_{2}, l\left(h_{1}\right) \neq l\left(h_{2}\right)$, then $l=$ $\max \left\{l\left(h_{1}\right), l\left(h_{2}\right)\right\}$. To have a correct comparison, the two IVHFEs $h_{1}$ and $h_{2}$ should have the same length $l$. If there are fewer elements in $h_{1}$ than in $h_{2}$, an extension of $h_{1}$ should be considered optimistically by repeating its maximum element until it has the same length with $h_{2}$.

Given three IVHFEs represented by $h, h_{1}$, and $h_{2}$, Chen et al. [37] defined some operations on them as follows.

Definition 10. Let $h, h_{1}$, and $h_{2}$ be three IVHFEs; then one has the following: 
(1) $h^{c}=\left\{\left[1-\gamma^{+}, 1-\gamma^{-}\right] \mid \gamma \in h\right\}$,

(2) $h_{1} \cup h_{2}=\left\{\left[\gamma_{1}^{-} \vee \gamma_{2}^{-}, \gamma_{1}^{+} \vee \gamma_{2}^{+}\right] \mid \gamma_{1} \in h_{1}, \gamma_{2} \in h_{2}\right\}$,

(3) $h_{1} \cap h_{2}=\left\{\left[\gamma_{1}^{-} \wedge \gamma_{2}^{-}, \gamma_{1}^{+} \wedge \gamma_{2}^{+}\right] \mid \gamma_{1} \in h_{1}, \gamma_{2} \in h_{2}\right\}$,

(4) $h^{\lambda}=\left\{\left[\left(\gamma_{1}^{-}\right)^{\lambda},\left(\gamma_{1}^{+}\right)^{\lambda}\right] \mid \gamma \in h\right\}, \lambda>0$,

(5) $\lambda h=\left\{\left[1-\left(1-\gamma^{-}\right)^{\lambda}, 1-\left(1-\gamma^{+}\right)^{\lambda}\right] \mid \gamma \in h\right\}, \lambda>0$,

(6) $h_{1} \oplus h_{2}=\left\{\left[\gamma_{1}^{-}+\gamma_{2}^{-}-\gamma_{1}^{-} \gamma_{2}^{-}, \gamma_{1}^{+}+\gamma_{2}^{+}-\gamma_{1}^{+} \gamma_{2}^{+}\right] \mid \gamma_{1} \in\right.$ $\left.h_{1}, \gamma_{2} \in h_{2}\right\}$

(7) $h_{1} \otimes h_{2}=\left\{\left[\gamma_{1}^{-} \gamma_{2}^{-}, \gamma_{1}^{+} \gamma_{2}^{+}\right] \mid \gamma_{1} \in h_{1}, \gamma_{2} \in h_{2}\right\}$.

Further, Chen et al. [37] established some relationships for the above operations on IVHFEs.

Theorem 11. Let $h, h_{1}$, and $h_{2}$ be three IVHFEs; one has the following:

(1) $h_{1} \oplus h_{2}=h_{2} \oplus h_{1}$,

(2) $h_{1} \otimes h_{2}=h_{2} \otimes h_{1}$,

(3) $\left(h_{1} \cup h_{2}\right)^{c}=h_{1}^{c} \cap h_{2}^{c}$,

(4) $\left(h_{1} \cap h_{2}\right)^{c}=h_{1}^{c} \cup h_{2}^{c}$,

(5) $(\lambda h)^{c}=\left(h^{c}\right)^{\lambda}$,

(6) $\left(h^{\lambda}\right)^{c}=\lambda\left(h^{c}\right)$

(7) $\left(h_{1} \oplus h_{2}\right)^{c}=h_{1}^{c} \otimes h_{2}^{c}$,

(8) $\left(h_{1} \otimes h_{2}\right)^{c}=h_{1}^{c} \oplus h_{2}^{c}$.

Example 12. Let $h_{1}=\{[0.5,0.6],[0.3,0.8],[0.3,0.6]\}$ and $h_{2}=$ $\{[0.4,0.5],[0.4,0.7]\}$ be two IVHFEs; then, by the operational laws of IVHFEs given in Definition 10, we have

$$
\begin{aligned}
& h_{1} \cup h_{2}=\left\{\left[\gamma_{1}^{-} \vee \gamma_{2}^{-}, \gamma_{1}^{+} \vee \gamma_{2}^{+}\right] \mid \gamma_{1} \in h_{1}, \gamma_{2} \in h_{2}\right\} \\
&=\{[0.5 \vee 0.4,0.6 \vee 0.5],[0.5 \vee 0.4,0.6 \vee 0.7], \\
& {[0.3 \vee 0.4,0.8 \vee 0.5],[0.3 \vee 0.4,0.8 \vee 0.7], } \\
& {[0.3 \vee 0.4,0.6 \vee 0.5],[0.3 \vee 0.4,0.6 \vee 0.7]\} } \\
&=\{[0.5,0.6],[0.5,0.7],[0.4,0.8],[0.4,0.8], \\
& {[0.4,0.6],[0.4,0.7]\}, } \\
& h_{1} \cap h_{2}=\left\{\left[\gamma_{1}^{-} \wedge \gamma_{2}^{-}, \gamma_{1}^{+} \wedge \gamma_{2}^{+}\right] \mid \gamma_{1} \in h_{1}, \gamma_{2} \in h_{2}\right\} \\
&=\{[0.5 \wedge 0.4,0.6 \wedge 0.5],[0.5 \wedge 0.4,0.6 \wedge 0.7], \\
& {[0.3 \wedge 0.4,0.8 \wedge 0.5],[0.3 \wedge 0.4,0.8 \wedge 0.7], } \\
& {[0.3 \wedge 0.4,0.6 \wedge 0.5],[0.3 \wedge 0.4,0.6 \wedge 0.7]\} } \\
&=\{[0.4,0.5],[0.4,0.6],[0.3,0.5],[0.3,0.7], {[0.3,0.5],[0.3,0.6]\}, }
\end{aligned}
$$

$$
\begin{aligned}
h_{1} \oplus h_{2}=\left\{\left[\gamma_{1}^{-}+\gamma_{2}^{-}-\gamma_{1}^{-} \gamma_{2}^{-}, \gamma_{1}^{+}+\gamma_{2}^{+}-\gamma_{1}^{+} \gamma_{2}^{+}\right] \mid\right. & \left.\gamma_{1} \in h_{1}, \gamma_{2} \in h_{2}\right\} \\
=\{[0.5+0.4-0.5 \cdot 0.4,0.6+0.5-0.6 \cdot 0.5], & {[0.5+0.4-0.5 \cdot 0.4,0.6+0.7-0.6 \cdot 0.7], } \\
& {[0.3+0.4-0.3 \cdot 0.4,0.8+0.5-0.8 \cdot 0.5], } \\
& {[0.3+0.4-0.3 \cdot 0.4,0.8+0.7-0.8 \cdot 0.7], } \\
& {[0.3+0.4-0.3 \cdot 0.4,0.6+0.5-0.6 \cdot 0.5], } \\
& {[0.3+0.4-0.3 \cdot 0.4,0.6+0.7-0.6 \cdot 0.7]\} } \\
=\{ & {[0.7,0.8],[0.7,0.88],[0.58,0.9],[0.58,0.94], } \\
& {[0.58,0.8],[0.58,0.88]\}, } \\
h_{1} \otimes h_{2}=\left\{\left[\gamma_{1}^{-} \gamma_{2}^{-}, \gamma_{1}^{+} \gamma_{2}^{+}\right] \mid \gamma_{1} \in h_{1}, \gamma_{2} \in h_{2}\right\} & \\
=\{ & {[0.5 \cdot 0.4,0.6 \cdot 0.5],[0.5 \cdot 0.4,0.6 \cdot 0.7], } \\
& {[0.3 \cdot 0.4,0.8 \cdot 0.5],[0.3 \cdot 0.4,0.8 \cdot 0.7], } \\
& {[0.3 \cdot 0.4,0.6 \cdot 0.5],[0.3 \cdot 0.4,0.6 \cdot 0.7]\} } \\
=\{[0.2,0.3],[0.2,0.42],[0.12,0.4],[0.12,0.56], & 0.3],[0.12,0.42]\} .
\end{aligned}
$$

From Example 12, we can see that the dimension of the derived IVHFE may increase as the addition or multiplicative operations are done, which may increase the complexity of the calculations. To overcome the difficulty, we develop some new methods to decrease the dimension of the derived IVHFE when operating the IVHFEs on the premise of the assumptions given by Chen et al. [37]. The adjusted operational laws are defined as follows.

Definition 13. Let $h, h_{1}$, and $h_{2}$ be three IVHFEs, and let $\lambda$ be a positive real number; then one has the following:

(1) $h^{c}=\left\{\left[1-h^{\sigma(k) U}, 1-h^{\sigma(k) L}\right] \mid k=1,2, \ldots, l\right\}$,

(2) $h_{1} \cup h_{2}=\left\{\left[h_{1}^{\sigma(k) L} \vee h_{2}^{\sigma(k) L}, h_{1}^{\sigma(k) U} \vee h_{2}^{\sigma(k) U}\right] \mid k=\right.$ $1,2, \ldots, l\}$,

(3) $h_{1} \cap h_{2}=\left\{\left[h_{1}^{\sigma(k) L} \wedge h_{2}^{\sigma(k) L}, h_{1}^{\sigma(k) U} \wedge h_{2}^{\sigma(k) U}\right] \mid k=\right.$ $1,2, \ldots, l\}$,

(4) $h^{\lambda}=\left\{\left[\left(h^{\sigma(k) L}\right)^{\lambda},\left(h^{\sigma(k) U}\right)^{\lambda}\right] \mid k=1,2, \ldots, l\right\}$,

(5) $\lambda h=\left\{\left[1-\left(1-h^{\sigma(k) L}\right)^{\lambda}, 1-\left(1-h^{\sigma(k) U}\right)^{\lambda}\right] \mid k=\right.$ $1,2, \ldots, l\}$,

(6) $h_{1} \oplus h_{2}=\left\{\left[h_{1}^{\sigma(k) L}+h_{2}^{\sigma(k) L}-h_{1}^{\sigma(k) L} h_{2}^{\sigma(k) L}, h_{1}^{\sigma(k) U}+h_{2}^{\sigma(k) U}-\right.\right.$ $\left.\left.h_{1}^{\sigma(k) U} h_{2}^{\sigma(k) U}\right] \mid k=1,2, \ldots, l\right\}$,

(7) $h_{1} \otimes h_{2}=\left\{\left[h_{1}^{\sigma(k) L} h_{2}^{\sigma(k) L}, h_{1}^{\sigma(k) U} h_{2}^{\sigma(k) U}\right] \mid k=1,2, \ldots, l\right\}$,

where $h_{j}^{\sigma(k)}=\left[h_{j}^{\sigma(k) L}, h_{j}^{\sigma(k) U}\right]$ is the $k$ th largest interval number in $h_{j}$. 
Theorem 14. Let $h, h_{1}$, and $h_{2}$ be three IVHFEs. For the new operations in Definition 13, one has the following:

(1) $h_{1} \oplus h_{2}=h_{2} \oplus h_{1}$,

(2) $h_{1} \otimes h_{2}=h_{2} \otimes h_{1}$,

(3) $\left(h_{1} \cup h_{2}\right)^{c}=h_{1}^{c} \cap h_{2}^{c}$,

(4) $\left(h_{1} \cap h_{2}\right)^{c}=h_{1}^{c} \cup h_{2}^{c}$,

(5) $(\lambda h)^{c}=\left(h^{c}\right)^{\lambda}$,

(6) $\left(h^{\lambda}\right)^{c}=\lambda\left(h^{c}\right)$,

(7) $\left(h_{1} \oplus h_{2}\right)^{c}=h_{1}^{c} \otimes h_{2}^{c}$,

(8) $\left(h_{1} \otimes h_{2}\right)^{c}=h_{1}^{c} \oplus h_{2}^{c}$.

Proof. The proofs are similar to Theorems 1 and 2 in [37].

Theorem 14 shows that Theorem 11 is still valid for the new operations in Definition 13.

Example 15. Reconsider Example 12. By (3) and assumptions given by Chen et al. [37]; then $h_{1}=\{[0.3,0.6],[0.3,0.8]$, $[0.5,0.6]\}$ and $h_{2}=\{[0.4,0.5],[0.4,0.7],[0.4,0.7]\}$. By virtue of Definition 13, we have

$$
\begin{aligned}
& h_{1} \cup h_{2}=\left\{\left[h_{1}^{\sigma(k) L} \vee h_{2}^{\sigma(k) L}, h_{1}^{\sigma(k) U} \vee h_{2}^{\sigma(k) U}\right] \mid k=1,2,3\right\} \\
& =\{[0.3 \vee 0.4,0.6 \vee 0.5],[0.3 \vee 0.4,0.8 \vee 0.7] \text {, } \\
& [0.5 \vee 0.4,0.6 \vee 0.7]\} \\
& =\{[0.4,0.6],[0.4,0.8],[0.5,0.7]\} \text {, } \\
& h_{1} \cap h_{2}=\left\{\left[h_{1}^{\sigma(k) L} \wedge h_{2}^{\sigma(k) L}, h_{1}^{\sigma(k) U} \wedge h_{2}^{\sigma(k) U}\right] \mid k=1,2,3\right\} \\
& =\{[0.3 \wedge 0.4,0.6 \wedge 0.5],[0.3 \wedge 0.4,0.8 \wedge 0.7] \text {, } \\
& [0.5 \wedge 0.4,0.6 \wedge 0.7]\} \\
& =\{[0.3,0.5],[0.3,0.7],[0.4,0.6]\} \text {, } \\
& h_{1} \oplus h_{2}=\left\{\left[h_{1}^{\sigma(k) L}+h_{2}^{\sigma(k) L}-h_{1}^{\sigma(k) L} h_{2}^{\sigma(k) L}\right.\right. \text {, } \\
& \left.\left.h_{1}^{\sigma(k) U}+h_{2}^{\sigma(k) U}-h_{1}^{\sigma(k) U} h_{2}^{\sigma(k) U}\right] \mid k=1,2,3\right\} \\
& =\{[0.3+0.4-0.3 \cdot 0.4,0.6+0.5-0.6 \cdot 0.5] \text {, } \\
& {[0.3+0.4-0.3 \cdot 0.4,0.8+0.7-0.8 \cdot 0.7] \text {, }} \\
& [0.5+0.4-0.5 \cdot 0.4,0.6+0.7-0.6 \cdot 0.7]\} \\
& =\{[0.58,0.8],[0.58,0.94],[0.7,0.88]\} \text {, } \\
& h_{1} \otimes h_{2}=\left\{\left[h_{1}^{\sigma(k) L} h_{2}^{\sigma(k) L}, h_{1}^{\sigma(k) U} h_{2}^{\sigma(k) U}\right] \mid k=1,2,3\right\} \\
& =\{[0.3 \cdot 0.4,0.6 \cdot 0.5],[0.3 \cdot 0.4,0.8 \cdot 0.7] \text {, } \\
& [0.5 \cdot 0.4,0.6 \cdot 0.7]\} \\
& =\{[0.12,0.3],[0.12,0.56],[0.2,0.42]\} \text {. }
\end{aligned}
$$

Comparing Example 12 with Example 15, we note that the adjusted operational laws given in Definition 13 indeed decrease the dimension of the derived IVHFE when operating the IVHFEs, which brings grievous advantage for the practicing application.

3.2. Concept of Interval-Valued Hesitant Fuzzy Soft Sets. In $[35,36,43]$, researchers have introduced the concept of hesitant fuzzy soft sets and developed some approaches to hesitant fuzzy soft sets based on decision making. However, incompleteness and inaccuracy of information in the process of making decision are very important problems we have to resolve. Due to insufficiency in available information, it is unreasonable for us to adopt hesitant fuzzy soft sets to deal with some decision making problems in which decision makers only quantify their opinions with several crisp numbers. Instead, the basic characteristics of the decisionmaking problems described by several interval numbers may overcome the difficulty. Based on the above fact, we extend hesitant fuzzy soft sets into the interval-valued hesitant fuzzy environment and introduce the concept of interval-valued hesitant fuzzy sets.

In this subsection, we first introduce the notion of interval-valued hesitant fuzzy soft sets, which is a hybrid model combining interval-valued hesitant fuzzy sets and soft sets.

Definition 16. Let $(U, E)$ be a soft universe and $A \subseteq E$. A pair $\mathfrak{S}=(\widetilde{F}, A)$ is called an interval-valued hesitant fuzzy soft set over $U$, where $\widetilde{F}$ is a mapping given by $\widetilde{F}: A \rightarrow \operatorname{IVHF}(U)$.

An interval-valued hesitant fuzzy soft set is a parameterized family of interval-valued hesitant fuzzy subsets of $U$. That is to say, $\widetilde{F}(e)$ is an interval-valued hesitant fuzzy subset in $U$, $\forall e \in A$. Following the standard notations, $\widetilde{F}(e)$ can be written as

$$
\widetilde{F}(e)=\{\langle x, \widetilde{F}(e)(x)\rangle: x \in U\} .
$$

Sometimes we write $\widetilde{F}$ as $(\widetilde{F}, E)$. If $A \subseteq E$, we can also have an interval-valued hesitant fuzzy soft set $(\widetilde{F}, A)$.

Example 17. Let $U$ be a set of four participants performing dance programme, which is denoted by $U=\left\{x_{1}, x_{2}, x_{3}, x_{4}\right\}$. Let $E$ be a parameter set, where $E=\left\{e_{1}, e_{2}, e_{3}\right\}=\{$ confident; creative; graceful $\}$. Suppose that three judges think the precise membership degrees of a candidate $x_{j}$ to a parameter $e_{i}$ are hard to be specified. To overcome this barrier, they represent the membership degrees of a candidate $x_{j}$ to a parameter $e_{i}$ with several possible interval values. Then interval-valued hesitant fuzzy soft set $\mathbb{S}=(\widetilde{F}, A)$ defined as follows gives the evaluation of the performance of candidates by three judges:

$$
\begin{aligned}
\widetilde{F}\left(e_{1}\right)=\{ & \left\langle x_{1},\{[0.6,0.8],[0.6,0.7],[0.8,0.9]\}\right\rangle, \\
& \left\langle x_{2},\{[0.4,0.5],[0.7,0.8],[0.6,0.8]\}\right\rangle, \\
& \left\langle x_{3},\{[0.7,0.8],[0.6,0.8],[0.7,0.8]\}\right\rangle, \\
& \left\langle x_{4},\{[0.8,0.9],[0.7,0.9],[0.8,1.0]\}\right\rangle,
\end{aligned}
$$


TABLE 1: Interval-valued hesitant fuzzy soft set $\mathfrak{S}=(\widetilde{F}, A)$.

\begin{tabular}{llcr}
\hline$U$ & $e_{1}$ & $e_{2}$ & $e_{3}$ \\
\hline$x_{1}$ & $\{[0.6,0.8],[0.6,0.7],[0.8,0.9]\}$ & $\{[0.5,0.6],[0.4,0.6],[0.5,0.7]\}$ & $\{[0.3,0.5],[0.4,0.7],[0.5,0.7]\}$ \\
$x_{2}$ & $\{[0.4,0.5],[0.7,0.8],[0.6,0.8]\}$ & $\{[0.7,0.8],[0.8,0.9],[0.7,0.8]\}$ & $\{[0.6,0.7],[0.5,0.8],[0.6,0.8]\}$ \\
$x_{3}$ & $\{[0.7,0.8],[0.6,0.8],[0.7,0.8]\}$ & $\{[0.6,0.9],[0.7,0.8],[0.7,0.9]\}$ & $\{[0.5,0.7],[0.6,0.8],[0.4,0.6]\}$ \\
$x_{4}$ & $\{[0.8,0.9],[0.7,0.9],[0.8,1.0]\}$ & $\{[0.6,0.7],[0.5,0.8],[0.6,0.8]\}$ & $\{[0.7,0.8],[0.8,0.9],[0.6,0.8]\}$ \\
\hline
\end{tabular}

$$
\begin{aligned}
& \widetilde{F}\left(e_{2}\right)=\{\left\langle x_{1},\{[0.5,0.6],[0.4,0.6],[0.5,0.7]\}\right\rangle, \\
&\left\langle x_{2},\{[0.7,0.8],[0.8,0.9],[0.7,0.8]\}\right\rangle, \\
&\left\langle x_{3},\{[0.6,0.9],[0.7,0.8],[0.7,0.9]\}\right\rangle, \\
&\left.\left\langle x_{4},\{[0.6,0.7],[0.5,0.8],[0.6,0.8]\}\right\rangle\right\}, \\
& \widetilde{F}\left(e_{3}\right)=\left\{\left\langle x_{1},\{[0.3,0.5],[0.4,0.7],[0.5,0.7]\}\right\rangle,\right. \\
&\left\langle x_{2},\{[0.6,0.7],[0.5,0.8],[0.6,0.8]\}\right\rangle, \\
&\left\langle x_{3},\{[0.5,0.7],[0.6,0.8],[0.4,0.6]\}\right\rangle, \\
&\left.\left\langle x_{4},\{[0.7,0.8],[0.8,0.9],[0.6,0.8]\}\right\rangle\right\} .
\end{aligned}
$$

The tabular representation of $\mathbb{S}=(\widetilde{F}, A)$ is shown in Table 1 .

All the available information on these participants performing dance programme can be characterized by an interval-valued hesitant fuzzy soft set $\mathbb{S}=(\widetilde{F}, A)$. In Table 1 , we can see that the precise evaluation for an alternative to satisfy a criterion is unknown while possible interval values of such an evaluation are given. For example, we cannot present the precise degree of how confident the candidate $x_{1}$ performing dance programme is; however, the degree to which the candidate $x_{1}$ performing dance programme is confident can be represented by three possible interval values $[0.6,0.8],[0.6,0.7]$, and $[0.8,0.9]$.

In what follows we will compare some existing soft sets model with the newly proposed interval-valued hesitant fuzzy soft sets by using several examples. Finally, we illustrate the rationality of the newly proposed interval-valued hesitant fuzzy soft sets.

Remark 18. In Definition 16, if there is only one element in the IVHFE $\widetilde{F}(e)(x)$, we can note that an interval-valued hesitant fuzzy soft set degenerates into an interval-valued fuzzy soft set [10]. That is to say, interval-valued hesitant fuzzy soft sets in Definition 16 are an extension of interval-valued fuzzy soft sets proposed by Yang et al. [10].

Example 19. Let $U$ be a set of four participants performing dance programme, which is denoted by $U=\left\{x_{1}, x_{2}, x_{3}, x_{4}\right\}$. Let $E$ be a parameter set, where $E=\left\{e_{1}, e_{2}, e_{3}\right\}=\{$ confident; creative; graceful\}. Now, assume that there is only a judge who is invited to evaluate the possible membership degrees of a candidate $x_{j}$ to a parameter $e_{i}$ with an interval value within $[0,1]$. In that case, the evaluation of the performance of candidates can be presented by an interval-valued fuzzy soft set which is defined as follows:

$$
\begin{array}{r}
\widetilde{F}\left(e_{1}\right)=\left\{\left\langle x_{1},[0.6,0.7]\right\rangle,\left\langle x_{2},[0.6,0.8]\right\rangle,\right. \\
\left.\left\langle x_{3},[0.7,0.8]\right\rangle,\left\langle x_{4},[0.7,0.9]\right\rangle\right\}, \\
\widetilde{F}\left(e_{2}\right)=\left\{\left\langle x_{1},[0.5,0.6]\right\rangle,\left\langle x_{2},[0.7,0.8]\right\rangle,\right. \\
\left.\left\langle x_{3},[0.6,0.9]\right\rangle,\left\langle x_{4},[0.5,0.8]\right\rangle\right\}, \\
\widetilde{F}\left(e_{3}\right)=\left\{\left\langle x_{1},[0.3,0.5]\right\rangle,\left\langle x_{2},[0.6,0.7]\right\rangle,\right. \\
\left.\left\langle x_{3},[0.4,0.6]\right\rangle,\left\langle x_{4},[0.6,0.8]\right\rangle\right\} .
\end{array}
$$

However, we point out that it is unreasonable to invite only an expert to develop the policy with an interval number because of the consideration of comprehension and rationality in the process of decision making. Therefore, in many decision making problems, it is necessary for decision makers to need several experts participating in developing the policy. Thus the decision results may be more comprehensive and reasonable. In this case, the evaluation of the performance of candidates can be described as an interval-valued hesitant fuzzy soft set which is defined in Example 17.

Comparing with the results of two models, we observe that interval-valued hesitant fuzzy soft sets contain more information than interval-valued fuzzy soft sets. Hence, we say that the available information in interval-valued hesitant fuzzy soft sets is more comprehensive and reasonable than interval-valued fuzzy soft sets, and interval-valued hesitant fuzzy soft sets are indeed an extension of interval-valued fuzzy soft sets proposed by Yang et al. [10].

Remark 20. When the upper and lower limits of all the interval values in the IVHFE $\widetilde{F}(e)(x)$ are identical, it should be noted that an interval-valued hesitant fuzzy soft set degenerates into a hesitant fuzzy soft set in $[35,36]$, which indicates that hesitant fuzzy soft sets are a special type of interval-valued hesitant fuzzy soft sets.

Example 21. Let $U$ be a set of four participants performing dance programme, which is denoted by $U=\left\{x_{1}, x_{2}, x_{3}, x_{4}\right\}$. Let $E$ be a parameter set, where $E=\left\{e_{1}, e_{2}, e_{3}\right\}=\{$ confident; creative; graceful\}. Now we suppose that there are three judges who are invited to evaluate the possible membership degrees of a candidate $x_{j}$ to a parameter $e_{i}$ with crisp numbers. In that case, the evaluation of the performance of 
candidates can be described as a hesitant fuzzy soft set defined as follows:

$$
\begin{array}{r}
\widetilde{F}\left(e_{1}\right)=\left\{\left\langle x_{1},\{0.6,0.7,0.8\}\right\rangle,\left\langle x_{2},\{0.5,0.7,0.8\}\right\rangle,\right. \\
\left.\left\langle x_{3},\{0.7,0.8,0.8\}\right\rangle,\left\langle x_{4},\{0.8,0.9,0.9\}\right\rangle\right\}, \\
\widetilde{F}\left(e_{2}\right)=\left\{\left\langle x_{1},\{0.5,0.6,0.7\}\right\rangle,\left\langle x_{2},\{0.7,0.8,0.8\}\right\rangle,\right. \\
\left.\left\langle x_{3},\{0.6,0.7,0.9\}\right\rangle,\left\langle x_{4},\{0.6,0.8,0.8\}\right\rangle\right\}, \\
\widetilde{F}\left(e_{3}\right)=\left\{\left\langle x_{1},\{0.4,0.5,0.7\}\right\rangle,\left\langle x_{2},\{0.6,0.7,0.7\}\right\rangle,\right. \\
\left.\left\langle x_{3},\{0.4,0.6,0.7\}\right\rangle,\left\langle x_{4},\{0.7,0.8,0.8\}\right\rangle\right\} .
\end{array}
$$

In this example, if the available information and the experience of experts are both short, it is unreasonable to exactly quantify their opinions by using several crisp numbers. Thus the decision makers are apt to lose information and may supply incorrect policies through using hesitant fuzzy soft set theory. But decision makers can overcome the difficulty by adopting several interval numbers. Thus the evaluation of the performance of candidates can be presented by intervalvalued hesitant fuzzy soft sets defined in Example 17.

Comparing with the results of two models, we see that the available information in interval-valued hesitant fuzzy soft sets is more comprehensive and scientific than hesitant fuzzy soft sets, and hesitant fuzzy soft sets are indeed a special case of interval-valued hesitant fuzzy soft sets.

Remark 22. If there is only one interval value in the IVHFE $\widetilde{F}(e)(x)$ whose upper and lower limits are identical, intervalvalued hesitant fuzzy soft sets in Definition 16 degenerate into the fuzzy soft set presented by Maji et al. in [12]. That is, the fuzzy soft sets presented by Maji et al. in [12] are a special case of interval-valued hesitant fuzzy soft sets defined by us.

Example 23. Let $U$ be a set of four participants performing dance programme, which is denoted by $U=\left\{x_{1}, x_{2}, x_{3}, x_{4}\right\}$. Let $E$ be a parameter set, where $E=\left\{e_{1}, e_{2}, e_{3}\right\}=\{$ confident; creative; graceful $\}$. Assume that there is a judge who is invited to evaluate the possible membership degrees of a candidate $x_{j}$ to a parameter $e_{i}$ with a crisp number. In that case, the evaluation of the performance of candidates can be described as fuzzy soft sets defined as follows:

$$
\begin{aligned}
& \widetilde{F}\left(e_{1}\right)=\frac{0.6}{x_{1}}+\frac{0.5}{x_{2}}+\frac{0.8}{x_{3}}+\frac{0.9}{x_{4}}, \\
& \widetilde{F}\left(e_{2}\right)=\frac{0.5}{x_{1}}+\frac{0.7}{x_{2}}+\frac{0.7}{x_{3}}+\frac{0.8}{x_{4}}, \\
& \widetilde{F}\left(e_{3}\right)=\frac{0.4}{x_{1}}+\frac{0.6}{x_{2}}+\frac{0.7}{x_{3}}+\frac{0.8}{x_{4}} .
\end{aligned}
$$

Now, we reconsider the example. On the one hand, in many decision making events, it is unreasonable to invite only an expert to develop the policy with a crisp number. Several experts participating in developing the policy can make the decision results more comprehensive and objective. On the other hand, if the experts' experience is short, it is very difficult for the experts to exactly quantify their opinions by using several crisp numbers. Instead, adopting interval numbers may overcome the difficulty. Considering the above two facts, the evaluation of the performance of candidates can be described as interval-valued hesitant fuzzy soft sets defined in Example 17.

Based on the above discussions, we can note that the available information in interval-valued hesitant fuzzy soft sets is more comprehensive and objective than fuzzy soft sets, and fuzzy soft sets are indeed a special type of interval-valued hesitant fuzzy soft sets.

From Remark 18, we can note that an interval-valued fuzzy soft set can be induced by an interval-valued hesitant fuzzy soft set. So we introduce reduct interval-valued fuzzy soft sets of interval-valued hesitant fuzzy soft sets.

Definition 24. The optimistic reduct interval-valued fuzzy soft set (ORIVFS) of an interval-valued hesitant fuzzy soft set $(\widetilde{F}, A)$ is defined as an interval-valued fuzzy soft set $\left(\widetilde{F}_{+}, A\right)$ over $U$ such that, for all $\gamma^{\sigma(k)} \in \widetilde{F}(e)(x)$,

$$
\begin{aligned}
\widetilde{F}_{+}(e) & =\left\{\left(x, \widetilde{F}_{+}(e)(x)\right): x \in U\right\} \\
& =\left\{\left(x, \bigvee_{k=1}^{l} \gamma^{\sigma(k)}\right): x \in U\right\}, \quad \forall e \in A,
\end{aligned}
$$

where $\gamma^{\sigma(k)}=\left[\gamma^{\sigma(k) L}, \gamma^{\sigma(k) U}\right]$ is the $k$ th largest interval number in the IVHFE $\widetilde{F}(e)(x)$ and $l$ stands for the number of interval numbers in the IVHFE $\widetilde{F}(e)(x)$.

Definition 25. The neutral reduct interval-valued fuzzy soft set (NRIVFS) of an interval-valued hesitant fuzzy soft set $(\widetilde{F}, A)$ is defined as an interval-valued fuzzy soft set $\left(\widetilde{F}_{N}, A\right)$ over $U$ such that, for all $\gamma^{\sigma(k)} \in \widetilde{F}(e)(x)$,

$$
\begin{aligned}
\widetilde{F}_{N}(e) & =\left\{\left(x, \widetilde{F}_{N}(e)(x)\right): x \in U\right\} \\
& =\left\{\left(x, \frac{1}{l} \sum_{k=1}^{l} \gamma^{\sigma(k)}\right): x \in U\right\}, \quad \forall e \in A,
\end{aligned}
$$

where $\gamma^{\sigma(k)}=\left[\gamma^{\sigma(k) L}, \gamma^{\sigma(k) U}\right]$ is the $k$ th largest interval number in the IVHFE $\widetilde{F}(e)(x)$ and $l$ stands for the number of interval numbers in the IVHFE $\widetilde{F}(e)(x)$.

To illustrate the notions presented above, we introduce the following example.

Example 26. Reconsider Example 17. By (3) and Definitions 24 and 25 , we can compute the ORIVFS $\left(\widetilde{F}_{+}, A\right)$ and NRIVFS $\left(\widetilde{F}_{N}, A\right)$ of the interval-valued hesitant fuzzy soft set $(\widetilde{F}, A)$ shown in Tables 2 and 3, respectively.

3.3. Operations on Interval-Valued Hesitant Fuzzy Soft Sets. In the above subsection, we have extended soft sets model into interval-valued hesitant fuzzy environment and presented interval-valued hesitant fuzzy soft sets. As the above subsection mentioned, interval-valued hesitant fuzzy soft sets 
TABLE 2: ORIVFS of $\mathfrak{S}=(\widetilde{F}, A)$.

\begin{tabular}{cccc}
\hline$U$ & $e_{1}$ & $e_{2}$ & $e_{3}$ \\
\hline$x_{1}$ & {$[0.8,0.9]$} & {$[0.5,0.7]$} & {$[0.5,0.7]$} \\
$x_{2}$ & {$[0.7,0.8]$} & {$[0.8,0.9]$} & {$[0.6,0.8]$} \\
$x_{3}$ & {$[0.7,0.8]$} & {$[0.7,0.9]$} & {$[0.6,0.8]$} \\
$x_{4}$ & {$[0.8,1.0]$} & {$[0.6,0.8]$} & {$[0.8,0.9]$} \\
\hline
\end{tabular}

TABLE 3: NRIVFS of $\mathfrak{S}=(\widetilde{F}, A)$.

\begin{tabular}{cccc}
\hline$U$ & $e_{1}$ & $e_{2}$ & $e_{3}$ \\
\hline$x_{1}$ & {$[0.67,0.70]$} & {$[0.47,0.63]$} & {$[0.40,0.63]$} \\
$x_{2}$ & {$[0.57,0.70]$} & {$[0.73,0.83]$} & {$[0.57,0.77]$} \\
$x_{3}$ & {$[0.67,0.80]$} & {$[0.67,0.87]$} & {$[0.50,0.70]$} \\
$x_{4}$ & {$[0.77,0.93]$} & {$[0.57,0.77]$} & {$[0.70,0.83]$} \\
\hline
\end{tabular}

are an extension of several soft sets model, such as intervalvalued fuzzy soft sets, hesitant fuzzy soft sets, and fuzzy soft sets. In these existing soft sets models, authors defined some operations on their own model, respectively. For example, Wang et al. [36] defined the complement, "AND," and "OR" operations on hesitant fuzzy soft sets. In [43], some new operations, such as ring sum and ring product, are also defined on hesitant fuzzy soft sets. Meanwhile, they also discussed some of the interesting properties. Along the lines of these works, we will further generalize those operations defined in these existing soft sets model to interval-valued hesitant fuzzy environment and present some new operations on intervalvalued hesitant fuzzy soft sets. Then some properties will be further established for such operations on interval-valued hesitant fuzzy soft sets.

In the subsection, unless otherwise stated, the operations on IVHFEs are carried out by the assumptions given by Chen et al. [37] and Definition 13 developed by us.

First, we give the definition of interval-valued hesitant fuzzy soft subsets.

Definition 27. Let $U$ be an initial universe and let $E$ be a set of parameters. Supposing that $A, B \subseteq E,(\widetilde{F}, A)$ and $(\widetilde{G}, B)$ are two interval-valued hesitant fuzzy soft sets, one says that $(\widetilde{F}, A)$ is an interval-valued hesitant fuzzy soft subset of $(\widetilde{G}, B)$ if and only if

(1) $A \subseteq B$,

(2) $\gamma_{1}^{\sigma(k)} \leq \gamma_{2}^{\sigma(k)}$,

where, for all $e \in A, x \in U, \gamma_{1}^{\sigma(k)}$, and $\gamma_{2}^{\sigma(k)}$ stand for the $k$ th largest interval number in the IVHFEs $\widetilde{F}(e)(x)$ and $\widetilde{G}(e)(x)$, respectively.

In this case, we write $(\widetilde{F}, A) \sqsubseteq(\widetilde{G}, B) .(\widetilde{F}, A)$ is said to be an interval-valued hesitant fuzzy soft super set of $(\widetilde{G}, B)$ if $(\widetilde{G}, B)$ is an interval-valued hesitant fuzzy soft subset of $(\widetilde{F}, A)$. We denote it by $(\widetilde{F}, A) \sqsupseteq(\widetilde{G}, B)$.

Example 28. Suppose that $U=\left\{x_{1}, x_{2}, x_{3}, x_{4}\right\}$ is an initial universe and $E=\left\{e_{1}, e_{2}, e_{3}\right\}$ is a set of parameters.
Let $A=\left\{e_{1}, e_{2}\right\}, B=E=\left\{e_{1}, e_{2}, e_{3}\right\}$. Two interval-valued hesitant fuzzy soft sets $(\widetilde{F}, A)$ and $(\widetilde{G}, A)$ are given as follows.

$$
\begin{aligned}
& \widetilde{F}\left(e_{1}\right)=\left\{\left\langle x_{1},\{[0.2,0.5],[0.3,0.6]\}\right\rangle,\right. \\
& \left\langle x_{2},\{[0.3,0.5],[0.4,0.7],[0.6,0.8]\}\right\rangle, \\
& \left\langle x_{3},\{[0.3,0.9],[0.5,0.8]\}\right\rangle, \\
& \left.\left\langle x_{4},\{[0.2,0.4],[0.5,0.7]\}\right\rangle\right\}, \\
& \widetilde{F}\left(e_{2}\right)=\left\{\left\langle x_{1},\{[0.1,0.4],[0.3,0.7],[0.3,0.8]\}\right\rangle\right. \text {, } \\
& \left\langle x_{2},\{[0.4,0.5],[0.5,0.6]\}\right\rangle, \\
& \left\langle x_{3},\{[0.2,0.4],[0.4,0.5]\}\right\rangle, \\
& \left.\left\langle x_{4},\{[0.2,0.3],[0.4,0.6]\}\right\rangle\right\}, \\
& \widetilde{G}\left(e_{1}\right)=\left\{\left\langle x_{1},\{[0.4,0.6],[0.2,0.9]\}\right\rangle,\right. \\
& \left\langle x_{2},\{[0.2,0.7],[0.3,0.9],[0.7,0.9]\}\right\rangle, \\
& \left\langle x_{3},\{[0.6,0.8]\}\right\rangle \text {, } \\
& \left.\left\langle x_{4},\{[0.3,0.5],[0.6,0.8],[0.7,0.8]\}\right\rangle\right\}, \\
& \widetilde{G}\left(e_{2}\right)=\left\{\left\langle x_{1},\{[0.3,0.5],[0.4,0.8]\}\right\rangle\right. \text {, } \\
& \left\langle x_{2},\{[0.3,0.7],[0.4,0.8]\}\right\rangle, \\
& \left\langle x_{3},\{[0.3,0.5],[0.3,0.7],[0.5,0.8]\}\right\rangle, \\
& \left.\left\langle x_{4},\{[0.3,0.5],[0.5,0.6]\}\right\rangle\right\}, \\
& \widetilde{G}\left(e_{3}\right)=\left\{\left\langle x_{1},\{[0.3,0.5],[0.5,0.6],[0.8,1.0]\}\right\rangle,\right. \\
& \left\langle x_{2},\{[0.55,0.6],[0.7,0.9]\}\right\rangle, \\
& \left\langle x_{3},\{[0.3,0.7],[0.8,0.85],[0.9,1.0]\}\right\rangle \text {, } \\
& \left.x_{4},\langle\{[0.7,0.9],[0.8,1.0]\}\rangle\right\} \text {. }
\end{aligned}
$$

By (3) and Definition 27, we have $(\widetilde{F}, A) \sqsubseteq(\widetilde{G}, B)$.

Definition 29. Let $(\widetilde{F}, A)$ and $(\widetilde{G}, B)$ be two interval-valued hesitant fuzzy soft sets. Now $(\widetilde{F}, A)$ and $(\widetilde{G}, B)$ are said to be interval-valued hesitant fuzzy soft equal if and only if
(1) $(\widetilde{F}, A) \sqsubseteq(\widetilde{G}, B)$,
(2) $(\widetilde{G}, B) \sqsubseteq(\widetilde{F}, A)$,

which can be denoted by $(\widetilde{F}, A)=(\widetilde{G}, B)$.

Definition 30. The complement of $(\widetilde{F}, A)$, denoted by $(\widetilde{F}, A)^{c}$, is defined by $(\widetilde{F}, A)^{c}=\left(\widetilde{F}^{c}, A\right)$, where $\widetilde{F}^{c}: A \rightarrow \operatorname{IVHF}(U)$ is a mapping given by $\widetilde{F}^{c}(e)$, for all $e \in A$, such that $\widetilde{F}^{c}(e)$ is the complement of interval-valued hesitant fuzzy set $\widetilde{F}(e)$ on $U$.

Clearly, we have $\left((\widetilde{F}, A)^{c}\right)^{c}=(\widetilde{F}, A)$. 
Example 31. Consider the interval-valued hesitant fuzzy soft set $(\widetilde{G}, B)$ over $U$ defined in Example 28. Thus, by Definition 30, we have

$$
\begin{aligned}
\widetilde{G}^{c}\left(e_{1}\right)= & \left\langle\left\langle x_{1},\{[0.1,0.8],[0.4,0.6]\}\right\rangle,\right. \\
& \left\langle x_{2},\{[0.1,0.3],[0.1,0.7],[0.3,0.8]\}\right\rangle, \\
& \left\langle x_{3},\{[0.2,0.4]\}\right\rangle, \\
& \left.\left\langle x_{4},\{[0.2,0.3],[0.2,0.4],[0.5,0.7]\}\right\rangle\right\}, \\
\widetilde{G}^{c}\left(e_{2}\right)= & \left\{\left\langle x_{1},\{[0.2,0.6],[0.5,0.7]\}\right\rangle,\right. \\
& \left\langle x_{2},\{[0.2,0.6],[0.3,0.7]\}\right\rangle, \\
& \left\langle x_{3},\{[0.2,0.5],[0.3,0.7],[0.5,0.7]\}\right\rangle, \\
& \left.\left\langle x_{4},\{[0.4,0.5],[0.5,0.7]\}\right\rangle\right\}, \\
\widetilde{G}^{c}\left(e_{3}\right)=\left\{\left\langle x_{1},\{[0.0,0.2],[0.4,0.5],[0.5,0.7]\}\right\rangle,\right. & \left\langle x_{2},\{[0.1,0.3],[0.4,0.45]\}\right\rangle, \\
& \left\langle x_{3},\{[0.0,0.1],[0.15,0.2],[0.3,0.7]\}\right\rangle, \\
& \left.\left\langle x_{4},\{[0.0,0.2],[0.1,0.3]\}\right\rangle\right\} .
\end{aligned}
$$

By the suggestions given by Molodtsov in [1], we present the notion of AND and OR operations on two interval-valued hesitant fuzzy soft sets as follows.

Definition 32. Let $(\widetilde{F}, A)$ and $(\widetilde{G}, B)$ be two interval-valued hesitant fuzzy soft sets over $U$. The " $(\widetilde{F}, A)$ AND $(\widetilde{G}, B)$," denoted by $(\widetilde{F}, A) \wedge(\widetilde{G}, B)$, is defined by

$$
(\widetilde{F}, A) \wedge(\widetilde{G}, B)=(\widetilde{H}, A \times B),
$$

where, for all $(\alpha, \beta) \in A \times B$,

$$
\begin{aligned}
\widetilde{H}(\alpha, \beta) & =\{\langle x, \widetilde{H}(\alpha, \beta)(x)\rangle: x \in U\} \\
& =\{\langle x, \widetilde{F}(\alpha)(x) \cap \widetilde{G}(\beta)(x)\rangle: x \in U\} .
\end{aligned}
$$

Definition 33. Let $(\widetilde{F}, A)$ and $(\widetilde{G}, B)$ be two interval-valued hesitant fuzzy soft sets over $U$. The "( $\widetilde{F}, A)$ OR $(\widetilde{G}, B)$," denoted by $(\widetilde{F}, A) \vee(\widetilde{G}, B)$, is defined by

$$
(\widetilde{F}, A) \vee(\widetilde{G}, B)=(\widetilde{I}, A \times B),
$$

where, for all $(\alpha, \beta) \in A \times B$,

$$
\begin{aligned}
\widetilde{I}(\alpha, \beta) & =\{\langle x, \widetilde{I}(\alpha, \beta)(x)\rangle: x \in U\} \\
& =\{\langle x, \widetilde{F}(\alpha)(x) \cup \widetilde{G}(\beta)(x)\rangle: x \in U\} .
\end{aligned}
$$

Example 34. Reconsider Example 28. Then we have $(\widetilde{F}, A) \wedge$ $(\widetilde{G}, B)=(\widetilde{H}, A \times B)$ and $(\widetilde{F}, A) \vee(\widetilde{G}, B)=(\widetilde{I}, A \times B)$ as follows:

$$
\begin{aligned}
& \widetilde{H}\left(e_{1}, e_{1}\right)=\{\left\langle x_{1},\{[0.2,0.5],[0.2,0.6]\}\right\rangle, \\
&\left\langle x_{2},\{[0.2,0.5],[0.3,0.7],[0.6,0.8]\}\right\rangle, \\
&\left\langle x_{3},\{[0.3,0.8],[0.5,0.8]\}\right\rangle, \\
&\left.\left\langle x_{4},\{[0.2,0.4],[0.5,0.7],[0.5,0.7]\}\right\rangle\right\}, \\
& \widetilde{H}\left(e_{1}, e_{2}\right)=\left\{\left\langle x_{1},\{[0.2,0.5],[0.3,0.6]\}\right\rangle,\right. \\
&\left\langle x_{2},\{[0.3,0.5],[0.4,0.7],[0.4,0.8]\}\right\rangle, \\
&\left\langle x_{3},\{[0.3,0.5],[0.3,0.7],[0.5,0.8]\}\right\rangle, \\
&\left.\left\langle x_{4},\{[0.2,0.4],[0.5,0.6]\}\right\rangle\right\},
\end{aligned}
$$

$$
\begin{aligned}
\widetilde{H}\left(e_{1}, e_{3}\right)=\{ & \left\langle x_{1},\{[0.2,0.5],[0.3,0.6],[0.3,0.6]\}\right\rangle, \\
& \left\langle x_{2},\{[0.3,0.5],[0.4,0.7],[0.6,0.8]\}\right\rangle, \\
& \left\langle x_{3},\{[0.3,0.7],[0.5,0.8],[0.5,0.8]\}\right\rangle, \\
& \left.\left\langle x_{4},\{[0.2,0.4],[0.5,0.7]\}\right\rangle\right\},
\end{aligned}
$$

$$
\begin{aligned}
\widetilde{H}\left(e_{2}, e_{1}\right)=\{ & \left\langle x_{1},\{[0.1,0.4],[0.2,0.7],[0.2,0.8]\}\right\rangle, \\
& \left\langle x_{2},\{[0.2,0.5],[0.3,0.6],[0.5,0.6]\}\right\rangle, \\
& \left\langle x_{3},\{[0.2,0.4],[0.4,0.5]\}\right\rangle, \\
& \left.\left\langle x_{4},\{[0.2,0.3],[0.4,0.6],[0.4,0.6]\}\right\rangle\right\},
\end{aligned}
$$

$$
\begin{aligned}
\widetilde{H}\left(e_{2}, e_{2}\right)=\{ & \left\langle x_{1},\{[0.1,0.4],[0.3,0.7],[0.3,0.8]\}\right\rangle, \\
& \left\langle x_{2},\{[0.3,0.5],[0.4,0.6]\}\right\rangle, \\
& \left\langle x_{3},\{[0.2,0.4],[0.3,0.5],[0.4,0.5]\}\right\rangle, \\
& \left.\left\langle x_{4},\{[0.2,0.3],[0.4,0.6]\}\right\rangle\right\},
\end{aligned}
$$

$$
\begin{aligned}
\widetilde{H}\left(e_{2}, e_{3}\right)=\{ & \left\langle x_{1},\{[0.1,0.4],[0.3,0.6],[0.3,0.8]\}\right\rangle, \\
& \left\langle x_{2},\{[0.4,0.5],[0.5,0.6]\}\right\rangle, \\
& \left\langle x_{3},\{[0.2,0.4],[0.4,0.5],[0.4,0.5]\}\right\rangle, \\
& \left.\left\langle x_{4},\{[0.2,0.3],[0.4,0.6]\}\right\rangle\right\},
\end{aligned}
$$

$$
\begin{aligned}
\widetilde{I}\left(e_{1}, e_{1}\right)=\{ & \left\langle x_{1},\{[0.4,0.6],[0.3,0.9]\}\right\rangle, \\
& \left\langle x_{2},\{[0.3,0.7],[0.4,0.9],[0.7,0.9]\}\right\rangle, \\
& \left\langle x_{3},\{[0.6,0.9],[0.6,0.8]\}\right\rangle, \\
& \left.\left\langle x_{4},\{[0.3,0.5],[0.6,0.8],[0.7,0.8]\}\right\rangle\right\},
\end{aligned}
$$$$
\widetilde{I}\left(e_{1}, e_{2}\right)=\left\{\left\langle x_{1},\{[0.3,0.5],[0.4,0.8]\}\right\rangle,\right.
$$$$
\left\langle x_{2},\{[0.3,0.7],[0.4,0.8],[0.6,0.8]\}\right\rangle,
$$$$
\left\langle x_{3},\{[0.3,0.9],[0.5,0.8],[0.5,0.8]\}\right\rangle \text {, }
$$$$
\left.\left\langle x_{4},\{[0.3,0.5],[0.5,0.7]\}\right\rangle\right\} \text {, }
$$ 


$$
\begin{aligned}
& \widetilde{I}\left(e_{1}, e_{3}\right)=\left\{\left\langle x_{1},\{[0.3,0.5],[0.5,0.6],[0.8,1.0]\}\right\rangle,\right. \\
&\left\langle x_{2},\{[0.55,0.6],[0.7,0.9],[0.7,0.9]\}\right\rangle, \\
&\left\langle x_{3},\{[0.3,0.9],[0.8,0.85],[0.9,1.0]\}\right\rangle, \\
&\left.\left\langle x_{4},\{[0.7,0.9],[0.8,1.0]\}\right\rangle\right\}, \\
& \widetilde{I}\left(e_{2}, e_{1}\right)=\left\{\left\langle x_{1},\{[0.4,0.6],[0.3,0.9],[0.3,0.9]\}\right\rangle,\right.\left\langle x_{2},\{[0.4,0.7],[0.5,0.9],[0.7,0.9]\}\right\rangle, \\
&\left\langle x_{3},\{[0.6,0.8],[0.6,0.8]\}\right\rangle, \\
&\left.\left\langle x_{4},\{[0.3,0.5],[0.6,0.8],[0.7,0.8]\}\right\rangle\right\}, \\
& \widetilde{I}\left(e_{2}, e_{2}\right)=\{\left\langle x_{1},\{[0.3,0.5],[0.4,0.8],[0.4,0.8]\}\right\rangle, \\
&\left\langle x_{2},\{[0.4,0.7],[0.5,0.8]\}\right\rangle, \\
&\left\langle x_{3},\{[0.3,0.5],[0.4,0.7],[0.5,0.8]\}\right\rangle, \\
&\left.\left\langle x_{4},\{[0.3,0.5],[0.5,0.6]\}\right\rangle\right\}, \\
&\left.\left\langle x_{4},\{[0.7,0.9],[0.8,1.0]\}\right\rangle\right\} . \\
&\left\langle x_{2},\{[0.55,0.6],[0.7,0.9]\}\right\rangle, \\
&\left\langle x_{3},\{[0.3,0.7],[0.8,0.85],[0.9,1.0]\}\right\rangle, \\
&\left.\left.\widetilde{I}\left(e_{2}, e_{3}\right)=\{0.5],[0.5,0.7],[0.8,1.0]\right\}\right\rangle,
\end{aligned}
$$

Theorem 35. Let $(\widetilde{F}, A)$ and $(\widetilde{G}, B)$ be two interval-valued hesitant fuzzy soft sets over $U$. Then one has the following:

(1) $((\widetilde{F}, A) \wedge(\widetilde{G}, B))^{c}=(\widetilde{F}, A)^{c} \vee(\widetilde{G}, B)^{c}$,

(2) $((\widetilde{F}, A) \vee(\widetilde{G}, B))^{c}=(\widetilde{F}, A)^{c} \wedge(\widetilde{G}, B)^{c}$.

Proof. (1) Suppose that $(\widetilde{F}, A) \wedge(\widetilde{G}, B)=(\widetilde{H}, A \times B)$. Therefore, by Definitions 30 and 32, we have $((\widetilde{F}, A) \wedge(\widetilde{G}, B))^{c}=(\widetilde{H}, A \times$ $B)^{c}=\left(\widetilde{H}^{c}, A \times B\right)$, where, for all $x \in U$ and $(\alpha, \beta) \in A \times$ $B, \widetilde{H}^{c}(\alpha, \beta)(x)=(\widetilde{F}(\alpha)(x) \cap \widetilde{G}(\beta)(x))^{c}$. From Theorem 14, it follows that $(\widetilde{F}(\alpha)(x) \cap \widetilde{G}(\beta)(x))^{c}=\widetilde{F}^{c}(\alpha)(x) \cup \widetilde{G}^{c}(\beta)(x)$.

On the other hand, by Definitions 30 and 33, we have $(\widetilde{F}, A)^{c} \vee(\widetilde{G}, B)^{c}=\left(\widetilde{F}^{c}, A\right) \vee\left(\widetilde{G}^{c}, B\right)=(\widetilde{I}, A \times B)$, where, for all $x \in U$ and $(\alpha, \beta) \in A \times B, \widetilde{I}(\alpha, \beta)(x)=\widetilde{F}^{c}(\alpha)(x) \cup \widetilde{G}^{c}(\beta)(x)$. Hence, $\left(\widetilde{H}^{c}, A \times B\right)=(\widetilde{I}, A \times B)$.

(2) The result can be proved in a similar way.

Theorem 36. Let $(\widetilde{F}, A),(\widetilde{G}, B)$, and $(\widetilde{H}, C)$ be three intervalvalued hesitant fuzzy soft sets over $U$. Then one has the following:

(1) $(\widetilde{F}, A) \wedge((\widetilde{G}, B) \wedge(\widetilde{H}, C))=((\widetilde{F}, A) \wedge(\widetilde{G}, B)) \wedge(\widetilde{H}, C)$,

(2) $(\widetilde{F}, A) \vee((\widetilde{G}, B) \vee(\widetilde{H}, C))=((\widetilde{F}, A) \vee(\widetilde{G}, B)) \vee(\widetilde{H}, C)$,

(3) $(\widetilde{F}, A) \wedge((\widetilde{G}, B) \vee(\widetilde{H}, C))=((\widetilde{F}, A) \wedge(\widetilde{G}, B)) \vee((\widetilde{F}, A) \wedge$ $(\widetilde{H}, C))$,

(4) $(\widetilde{F}, A) \vee((\widetilde{G}, B) \wedge(\widetilde{H}, C))=((\widetilde{F}, A) \vee(\widetilde{G}, B)) \wedge((\widetilde{F}, A) \vee$ $(\widetilde{H}, C))$.
Proof. (1) Consider $\forall x \in U, \alpha \in A, \beta \in B$, and $\gamma \in C$, we have $\widetilde{F}(\alpha)(x) \cap(\widetilde{G}(\beta)(x) \cap \widetilde{H}(\gamma)(x))=(\widetilde{F}(\alpha)(x) \cap \widetilde{G}(\beta)(x)) \cap$ $\widetilde{H}(\gamma)(x)$, from which we can conclude that $(\widetilde{F}, A) \wedge((\widetilde{G}, B) \wedge$ $(\widetilde{H}, C))=((\widetilde{F}, A) \wedge(\widetilde{G}, B)) \wedge(\widetilde{H}, C)$ holds.

Similar to the above progress, the proofs of (2), (3), and (4) can be made.

Remark 37. Suppose that $(\widetilde{F}, A)$ and $(\widetilde{G}, B)$ are two intervalvalued hesitant fuzzy soft sets over $U$. It is noted that, for all $(\alpha, \beta) \in A \times B$, if $\alpha \neq \beta$, then $(\widetilde{G}, B) \wedge(\widetilde{F}, A) \neq(\widetilde{F}, A) \wedge(\widetilde{G}, B)$, and $(\widetilde{G}, B) \vee(\widetilde{F}, A) \neq(\widetilde{F}, A) \vee(\widetilde{G}, B)$.

Next, on the basis of the operations in Definition 13, we first present ring sum and ring product operations on interval-valued hesitant fuzzy soft sets.

Definition 38. The ring sum operation on the two intervalvalued hesitant fuzzy soft sets $\widetilde{F}$ and $\widetilde{G}$ over $U$, denoted by $\widetilde{F} \oplus \widetilde{G}=\widetilde{H}$, is a mapping given by

$$
\widetilde{H}: E \longrightarrow \operatorname{IVHF}(U)
$$

such that, for all $e \in E$,

$$
\begin{aligned}
\widetilde{H}(e) & =\{\langle x, \widetilde{H}(e)(x)\rangle: x \in U\} \\
& =\{\langle x, \widetilde{F}(e)(x) \oplus \widetilde{G}(e)(x)\rangle: x \in U\}
\end{aligned}
$$

Definition 39. The ring product operation on the two interval-valued hesitant fuzzy soft sets $\widetilde{F}$ and $\widetilde{G}$ over $U$, denoted by $\widetilde{F} \otimes \widetilde{G}=\widetilde{H}$, is a mapping given by

$$
\widetilde{H}: E \longrightarrow \operatorname{IVHF}(U)
$$

such that, for all $e \in E$,

$$
\begin{aligned}
\widetilde{H}(e) & =\{\langle x, \widetilde{H}(e)(x)\rangle: x \in U\} \\
& =\{\langle x, \widetilde{F}(e)(x) \otimes \widetilde{G}(e)(x)\rangle: x \in U\} .
\end{aligned}
$$

Example 40. Let us consider the interval-valued hesitant fuzzy soft set $\widetilde{G}$ in Example 28. Let $\widetilde{F}$ be another intervalvalued hesitant fuzzy soft set over $U$ defined as follows:

$$
\begin{aligned}
\widetilde{F}\left(e_{1}\right)=\{ & \left\langle x_{1},\{[0.3,0.5],[0.3,0.8]\}\right\rangle, \\
& \left\langle x_{2},\{[0.1,0.5],[0.2,0.5],[0.4,0.7]\}\right\rangle, \\
& \left\langle x_{3},\{[0.2,0.5],[0.3,0.6],[0.5,0.8]\}\right\rangle, \\
& \left.\left\langle x_{4},\{[0.3,0.4],[0.5,0.7]\}\right\rangle\right\},
\end{aligned}
$$




$$
\begin{aligned}
& \widetilde{F}\left(e_{2}\right)=\{\left\langle x_{1},\{[0.4,0.5],[0.3,0.7]\}\right\rangle, \\
&\left\langle x_{2},\{[0.2,0.6],[0.3,0.6]\}\right\rangle, \\
&\left\langle x_{3},\{[0.2,0.3],[0.3,0.4],[0.5,0.8]\}\right\rangle, \\
&\left.\left\langle x_{4},\{[0.2,0.4],[0.4,0.6]\}\right\rangle\right\}, \\
& \widetilde{F}\left(e_{3}\right)=\left\{\left\langle x_{1},\{[0.2,0.5],[0.4,0.7]\}\right\rangle,\right. \\
&\left\langle x_{2},\{[0.5,0.6],[0.5,0.8]\}\right\rangle, \\
&\left\langle x_{3},\{[0.3,0.5],[0.2,0.7],[0.3,0.8]\}\right\rangle, \\
&\left.\left\langle x_{4},\{[0.3,0.5],[0.2,0.7]\}\right\rangle\right\}
\end{aligned}
$$

Then, by Definition 38, we have

$$
\begin{aligned}
(\widetilde{F} \oplus \widetilde{G})\left(e_{1}\right) & \\
= & \left\langle x_{1},\{[0.58,0.8],[0.44,0.98]\}\right\rangle, \\
& \left\langle x_{2},\{[0.28,0.85],[0.44,0.95],[0.82,0.97]\}\right\rangle, \\
& \left\langle x_{3},\{[0.68,0.9],[0.72,0.92],[0.8,0.96]\}\right\rangle, \\
& \left.\left\langle x_{4},\{[0.51,0.7],[0.8,0.94],[0.85,0.94]\}\right\rangle\right\}, \\
(\widetilde{F} \oplus \widetilde{G})\left(e_{2}\right) & \\
=\left\{\left\langle x_{1},\{[0.58,0.75],[0.58,0.94]\}\right\rangle,\right. & \left\langle x_{2},\{[0.44,0.88],[0.58,0.92]\}\right\rangle, \\
& \left\langle x_{3},\{[0.44,0.65],[0.51,0.82],[0.75,0.96]\}\right\rangle, \\
& \left.\left\langle x_{4},\{[0.44,0.7],[0.7,0.84]\}\right\rangle\right\}, \\
(\widetilde{F} \oplus \widetilde{G})\left(e_{3}\right) & \\
= & \left\langle\left\langle x_{1},\{[0.44,0.75],[0.7,0.88],[0.88,1.0]\}\right\rangle,\right. \\
& \left\langle x_{2},\{[0.775,0.84],[0.85,0.98]\}\right\rangle, \\
& \left\langle x_{3},\{[0.51,0.85],[0.84,0.955],[0.93,1.0]\}\right\rangle, \\
& \left.\left\langle x_{4},\{[0.79,0.95],[0.84,1.0]\}\right\rangle\right\} .
\end{aligned}
$$

By Definition 39, then

$$
\begin{aligned}
(\widetilde{F} \otimes \widetilde{G}) & \left(e_{1}\right) \\
= & \left\{\left\langle x_{1},\{[0.12,0.3],[0.06,0.72]\}\right\rangle,\right. \\
& \left\langle x_{2},\{[0.02,0.35],[0.06,0.45],[0.28,0.63]\}\right\rangle, \\
& \left\langle x_{3},\{[0.12,0.4],[0.18,0.48],[0.3,0.64]\}\right\rangle, \\
& \left.\left\langle x_{4},\{[0.09,0.2],[0.3,0.56],[0.35,0.56]\}\right\rangle\right\},
\end{aligned}
$$

$$
\begin{aligned}
(\widetilde{F} \otimes \widetilde{G} & \left(e_{2}\right) \\
=\{ & \left\langle x_{1},\{[0.12,0.25],[0.12,0.56]\}\right\rangle, \\
& \left\langle x_{2},\{[0.06,0.42],[0.12,0.48]\}\right\rangle, \\
& \left\langle x_{3},\{[0.06,0.15],[0.09,0.28],[0.25,0.64]\}\right\rangle, \\
& \left.\left\langle x_{4},\{[0.06,0.2],[0.2,0.36]\}\right\rangle\right\}, \\
(\widetilde{F} \otimes \widetilde{G})\left(e_{3}\right) & \\
=\left\{\left\langle x_{1},\{[0.06,0.25],[0.2,0.42],[0.32,0.7]\}\right\rangle,\right. & \left\langle x_{2},\{[0.275,0.36],[0.35,0.72]\}\right\rangle, \\
& \left\langle x_{3},\{[0.09,0.35],[0.16,0.595],[0.27,0.8]\}\right\rangle, \\
& \left.\left\langle x_{4},\{[0.21,0.45],[0.16,0.7]\}\right\rangle\right\} .
\end{aligned}
$$

Theorem 41. Let $\widetilde{F}$ and $\widetilde{G}$ be two interval-valued hesitant fuzzy soft sets over $U$. Then the following laws are valid:

(1) $\widetilde{F} \oplus \widetilde{G}=\widetilde{G} \oplus \widetilde{F}$,

(2) $\widetilde{F} \otimes \widetilde{G}=\widetilde{G} \otimes \widetilde{F}$,

(3) $(\widetilde{F} \oplus \widetilde{G})^{c}=\widetilde{F}^{c} \otimes \widetilde{G}^{c}$,

(4) $(\widetilde{F} \otimes \widetilde{G})^{c}=\widetilde{F}^{c} \oplus \widetilde{G}^{c}$.

Proof. The proof directly follows from Definitions 38 and 39 and Theorem 14.

Theorem 42. Let $\widetilde{F}, \widetilde{G}$, and $\widetilde{H}$ be any three interval-valued hesitant fuzzy soft sets over $U$; then the following hold:

(1) $(\widetilde{F} \oplus \widetilde{G}) \oplus \widetilde{H}=\widetilde{F} \oplus(\widetilde{G} \oplus \widetilde{H})$,

(2) $(\widetilde{F} \otimes \widetilde{G}) \otimes \widetilde{H}=\widetilde{F} \otimes(\widetilde{G} \otimes \widetilde{H})$.

Proof. The properties follow from Definitions 13, 38, and 39.

Definition 43. An interval-valued hesitant fuzzy soft set is said to be an empty interval-valued hesitant fuzzy soft set, denoted by $\widetilde{\varnothing}$, if $\widetilde{F}: E \rightarrow \operatorname{IVHF}(U)$, such that $\widetilde{F}(e)=$ $\{\langle x, \widetilde{F}(e)(x)\rangle: x \in U\}=\{\langle x,\{[0,0]\}\rangle: x \in U\}, \forall e \in E$.

Definition 44. An interval-valued hesitant fuzzy soft set is said to be a full interval-valued hesitant fuzzy soft set, denoted by $\widetilde{U}$, if $\widetilde{F}: E \rightarrow \operatorname{IVHF}(U)$, such that $\widetilde{F}(e)=\{\langle x, \widetilde{F}(e)(x)\rangle$ : $x \in U\}=\{\langle x,\{[1,1]\}\rangle: x \in U\}, \forall e \in E$.

From Definitions 43 and 44, obviously we have
(1) $\widetilde{\varnothing} \sqsubseteq \widetilde{F} \sqsubseteq \widetilde{U}$,
(2) $\widetilde{\varnothing}^{c}=\widetilde{U}$,
(3) $\widetilde{U}^{c}=\widetilde{\varnothing}$.

Theorem 45. Let $\widetilde{F}$ be an interval-valued hesitant fuzzy soft set over $U$; then the following hold: 
(1) $\widetilde{F} \vee \widetilde{\varnothing}=\widetilde{F}, \widetilde{F} \wedge \widetilde{\varnothing}=\widetilde{\varnothing}$,

(2) $\widetilde{F} \vee \widetilde{U}=\widetilde{U}, \widetilde{F} \wedge \widetilde{U}=\widetilde{F}$,

(3) $\widetilde{F} \oplus \widetilde{\varnothing}=\widetilde{F}, \widetilde{F} \otimes \widetilde{\varnothing}=\widetilde{\varnothing}$,

(4) $\widetilde{F} \oplus \widetilde{U}=\widetilde{U}, \widetilde{F} \otimes \widetilde{U}=\widetilde{F}$.

Proof. The proof is straightforward.

Remark 46. Let $\widetilde{F}$ be an interval-valued hesitant fuzzy soft set over $U$. If $\widetilde{F} \neq \widetilde{U}$ or $\widetilde{F} \neq \widetilde{\varnothing}$, then $\widetilde{F} \vee \widetilde{F}^{c} \neq \widetilde{U}$, and $\widetilde{F} \wedge \widetilde{F}^{c} \neq \widetilde{\varnothing}$.

Remark 47. Let $\widetilde{F}$ be an interval-valued hesitant fuzzy soft set over $U$. If $\widetilde{F} \neq \widetilde{U}$ or $\widetilde{F} \neq \widetilde{\varnothing}$, then $\widetilde{F} \oplus \widetilde{F}^{c} \neq \widetilde{U}$, and $\widetilde{F} \otimes \widetilde{F}^{c} \neq \widetilde{\varnothing}$.

\section{An Adjustable Approach to Interval-Valued Hesitant Fuzzy Soft Sets Based on Decision Making}

After interval-valued hesitant fuzzy sets were introduced by Chen et al. [37], interval-valued hesitant fuzzy sets have been used in handling many fuzzy decision making problems [38-40]. With the development of soft sets, the application of fuzzy soft sets in solving decision making problems has been investigated by many researchers [13-15]. In the current section, we will present an adjustable approach to intervalvalued hesitant fuzzy soft sets based on decision making. In the following, we will introduce the concept of level hesitant fuzzy soft sets of interval-valued hesitant fuzzy soft sets.

Definition 48. Let $\mathfrak{S}=(\widetilde{F}, A)$ be the interval-valued hesitant fuzzy soft set over $U$, where $A \subseteq E$ and $E$ is the parameter set. For $t \in \operatorname{Int}[0,1]$ and $\gamma^{\sigma(k)} \in \widetilde{F}(e)(x)(k=1,2, \ldots, l)$, we define

$$
\alpha^{\sigma(k)}= \begin{cases}1, & \gamma^{\sigma(k)} \geq t, \\ 0, & \gamma^{\sigma(k)}<t,\end{cases}
$$

where Int $[0,1]$ stands for the set of all closed subintervals of $[0,1]$ and $\gamma^{\sigma(k)}=\left[\gamma^{\sigma(k) L}, \gamma^{\sigma(k) U}\right]$ is the $k$ th largest interval number in the IVHFE $\widetilde{F}(e)(x)$. Then the hesitant fuzzy soft set $\left(\widetilde{F}_{t}, A\right)$, called a $t$-level hesitant fuzzy soft set $L(\widetilde{S} ; t)=\left(\widetilde{F}_{t}, A\right)$, is defined by

$$
\begin{aligned}
\widetilde{F}_{t}(e) & =L(\widetilde{F}(e) ; t) \\
& =\left\{\left\langle x, \widetilde{F}_{t}(e)(x)\right\rangle: x \in U\right\}=\left\{\left\langle x,\left\{\alpha^{\sigma(k)}\right\}\right\rangle: x \in U\right\},
\end{aligned}
$$

for all $e \in A$.

Remark 49. In Definition 48, it is worth noting that $t$ which is viewed as a given threshold is not a real number but an interval value belonging to $\operatorname{Int}[0,1]$ on membership values. In practical applications, these interval value thresholds are in advance given by decision makers according to their requirements on "membership levels." It is easy to see that HFEs of level hesitant fuzzy soft sets consist of 1 and 0 , which is very important in real-life applications of interval-valued hesitant fuzzy soft sets based on decision making.
TABLE 4: Tabular representation of $L(\mathfrak{S} ;[0.6,0.8])$.

\begin{tabular}{lccc}
\hline$U$ & $e_{1}$ & $e_{2}$ & $e_{3}$ \\
\hline$x_{1}$ & $\{1,0,1\}$ & $\{0,0,0\}$ & $\{0,0,0\}$ \\
$x_{2}$ & $\{0,1,1\}$ & $\{1,1,1\}$ & $\{0,0,1\}$ \\
$x_{3}$ & $\{1,1,1\}$ & $\{1,1,1\}$ & $\{0,1,0\}$ \\
$x_{4}$ & $\{1,1,1\}$ & $\{0,0,1\}$ & $\{1,1,1\}$ \\
\hline
\end{tabular}

To illustrate Definition 48, let us consider the intervalvalued hesitant fuzzy soft set $(\widetilde{F}, A)$ shown in Example 17 .

Example 50 (the $[0.6,0.8]$-level hesitant fuzzy soft set of the interval-valued hesitant fuzzy soft set $\mathbb{5}$ ). Reconsider Example 17. Now taking $t=[0.6,0.8]$, then, by (3) and Definition 48, we have the following $[0.6,0.8]$-level hesitant fuzzy soft sets:

$$
\begin{aligned}
& L\left(\widetilde{F}\left(e_{1}\right) ;[0.6,0.8]\right)=\left\{\left\langle x_{1},\{1,0,1\}\right\rangle,\left\langle x_{2},\{0,1,1\}\right\rangle,\right. \\
& \left.\left\langle x_{3},\{1,1,1\}\right\rangle,\left\langle x_{4},\{1,1,1\}\right\rangle\right\}, \\
& L\left(\widetilde{F}\left(e_{2}\right) ;[0.6,0.8]\right)=\left\{\left\langle x_{1},\{0,0,0\}\right\rangle,\left\langle x_{2},\{1,1,1\}\right\rangle,\right. \\
& \left.\left\langle x_{3},\{1,1,1\}\right\rangle,\left\langle x_{4},\{0,0,1\}\right\rangle\right\}, \\
& L\left(\widetilde{F}\left(e_{3}\right) ;[0.6,0.8]\right)=\left\{\left\langle x_{1},\{0,0,0\}\right\rangle,\left\langle x_{2},\{0,0,1\}\right\rangle,\right. \\
& \left.\left\langle x_{3},\{0,1,0\}\right\rangle,\left\langle x_{4},\{1,1,1\}\right\rangle\right\} \text {. }
\end{aligned}
$$

Then the $[0.6,0.8]$-level hesitant fuzzy soft set of $\mathfrak{S}=$ $(\widetilde{F}, A)$ is a special hesitant fuzzy soft set $L(\widetilde{\Im} ;[0.6,0.8])=$ $\left(\widetilde{F}_{[0.6,0.8]}, A\right)$, where, for $x_{j} \in U$, HFEs of the hesitant fuzzy sets $\widetilde{F}_{[0.6,0.8]}\left(e_{i}\right)=L\left(\widetilde{F}\left(e_{i}\right) ;[0.6,0.8]\right)$ consist of 1 and 0 . For example, $\widetilde{F}_{[0.6,0.8]}\left(e_{1}\right)\left(x_{2}\right)=L\left(\widetilde{F}\left(e_{1}\right)\left(x_{2}\right) ;[0.6,0.8]\right)=$ $\{0,1,1\}$, which means that the second judge and the third judge think the performance of candidate $x_{2}$ is confident on the membership degree $[0.6,0.8]$.

Table 4 gives the tabular representation of the level hesitant fuzzy soft set $L(\mathfrak{S} ;[0.6,0.8])$.

In Definition 48, we can note that the level threshold is always a constant interval value $t \in \operatorname{Int}[0,1]$. However, in the process of making decision, decision makers may impose different thresholds on different parameters. So we substitute a function for the constant interval value as the thresholds on the membership value to address this issue.

Definition 51. Let $(\widetilde{F}, A)$ be the interval-valued hesitant fuzzy soft set over $U$, where $A \subseteq E$ and $E$ is the parameter set. Let $\lambda: A \rightarrow \operatorname{Int}[0,1]$ be an interval-valued fuzzy set in $A$ which is called a threshold interval-valued fuzzy set. For $x \in U$, and $\gamma^{\sigma(k)} \in \widetilde{F}(e)(x)(k=1,2, \ldots, l)$, one defines

$$
\alpha^{\sigma(k)}= \begin{cases}1, & \gamma^{\sigma(k)} \geq \lambda(e), \\ 0, & \gamma^{\sigma(k)}<\lambda(e) .\end{cases}
$$


Then the hesitant fuzzy soft set $\left(\widetilde{F}_{\lambda}, A\right)$, called a level hesitant fuzzy soft set $L(\widetilde{S} ; \lambda(e))=\left(\widetilde{F}_{\lambda}, A\right)$ with respect to the fuzzy set $\lambda$, is defined by

$$
\begin{aligned}
\widetilde{F}_{\lambda}(e) & =L(\widetilde{F}(e) ; \lambda(e)) \\
& =\left\{\left\langle x, \widetilde{F}_{\lambda}(e)(x)\right\rangle: x \in U\right\}=\left\{\left\langle x,\left\{\alpha^{\sigma(k)}\right\}\right\rangle: x \in U\right\},
\end{aligned}
$$

for all $e \in A$.

In order to better understand the above definition, let us consider the following examples.

Example 52 (the mid-level of interval-valued hesitant fuzzy soft set). Let $\mathbb{S}=(\widetilde{F}, A)$ be an interval-valued hesitant fuzzy soft sets over $U$, where $A \subseteq E$ and $E$ is the parameter set. Suppose that $\left(\widetilde{F}_{N}, A\right)$ is a neutral reduct interval-valued fuzzy soft set of the interval-valued hesitant fuzzy soft set $\mathfrak{S}=(\widetilde{F}, A)$ defined by Definition 25 . Based on the neutral reduct interval-valued fuzzy soft set $\left(\widetilde{F}_{N}, A\right)$, we can define an interval-valued fuzzy set $\operatorname{mid}_{\mathfrak{S}}: A \rightarrow \operatorname{Int}[0,1]$ by

$$
\operatorname{mid}_{\mathfrak{S}}(e)=\frac{1}{|U|} \sum_{x \in U} \widetilde{F}_{N}(e)(x),
$$

for all $e \in A$. The interval-valued fuzzy set $\operatorname{mid}_{\mathbb{S}}$ is called the mid-threshold of the interval-valued hesitant fuzzy soft set $\mathfrak{S}$. Moreover, the level hesitant fuzzy soft set of the interval-valued hesitant fuzzy soft set $\mathbb{\mathfrak { S }}$ with respect to the mid-threshold interval-valued fuzzy set $\operatorname{mid}_{\mathfrak{S}}$, namely, $L\left(\mathfrak{S} ; \operatorname{mid}_{\mathfrak{S}}\right)$, is called the mid-level hesitant fuzzy soft set of 5 which is simply denoted as $L(\mathbb{\Im} ;$ mid). In the discussions below, the mid-level decision rule means that we will adopt the mid-threshold and consider the mid-level hesitant fuzzy soft set in interval-valued hesitant fuzzy soft sets based on decision making.

Reconsider the interval-valued hesitant fuzzy soft set $\mathbb{\mathfrak { S }}=$ $(\widetilde{F}, A)$ with its tabular representation shown in Table 1 . Table 3 gives the tabular representation of the neutral reduct intervalvalued fuzzy soft set $\left(\widetilde{F}_{N}, A\right)$ of $\mathfrak{\mathbb { S }}$. From Table 3 , the midthreshold $\operatorname{mid}_{\mathfrak{S}}$ of $\mathfrak{S}$ can be given as follows:

$$
\begin{gathered}
\operatorname{mid}_{\mathfrak{S}}=\left\{\left(e_{1},[0.67,0.7825]\right),\left(e_{2},[0.61,0.775]\right),\right. \\
\left.\left(e_{3},[0.5425,0.7325]\right)\right\},
\end{gathered}
$$

and the mid-level hesitant fuzzy soft set of $\mathbb{\subseteq}$ is a special hesitant fuzzy soft set $L(\widetilde{\Im}$; mid) with its tabular representation given by Table 5 .

Example 53 (the top-level of interval-valued hesitant fuzzy soft set). Let $\mathbb{S}=(\widetilde{F}, A)$ be interval-valued hesitant fuzzy soft sets over $U$, where $A \subseteq E$ and $E$ is the parameter set. Suppose that $\left(\widetilde{F}_{+}, A\right)$ is an optimistic reduct intervalvalued fuzzy soft set defined by Definition 24. Based on the optimistic reduct interval-valued fuzzy soft set $\left(\widetilde{F}_{+}, A\right)$, we can define an interval-valued fuzzy set $\max _{\mathfrak{S}}: A \rightarrow \operatorname{Int}[0,1]$ by

$$
\max _{\mathfrak{S}}(e)=\max _{x \in U} \widetilde{F}_{+}(e)(x),
$$

TABLE 5: Tabular representation of $L(\widetilde{S}$; mid).

\begin{tabular}{ccccc}
\hline$U$ & $e_{1}$ & $e_{2}$ & $e_{3}$ & Choice value $\left(c_{j}\right)$ \\
\hline$x_{1}$ & $\{0,0,1\}$ & $\{0,0,0\}$ & $\{0,0,0\}$ & $c_{1}=1$ \\
$x_{2}$ & $\{0,1,0\}$ & $\{1,1,1\}$ & $\{1,1,1\}$ & $c_{2}=7$ \\
$x_{3}$ & $\{1,0,1\}$ & $\{1,1,1\}$ & $\{0,1,0\}$ & $c_{3}=6$ \\
$x_{4}$ & $\{1,1,1\}$ & $\{0,0,1\}$ & $\{1,1,1\}$ & $c_{4}=7$ \\
\hline
\end{tabular}

TABLE 6: Tabular representation of $L(\mathbb{S}$; max).

\begin{tabular}{ccccc}
\hline$U$ & $e_{1}$ & $e_{2}$ & $e_{3}$ & Choice value $\left(c_{j}\right)$ \\
\hline$x_{1}$ & $\{0,0,0\}$ & $\{0,0,0\}$ & $\{0,0,0\}$ & $c_{1}=0$ \\
$x_{2}$ & $\{0,0,0\}$ & $\{0,1,0\}$ & $\{0,0,0\}$ & $c_{1}=1$ \\
$x_{3}$ & $\{0,0,0\}$ & $\{0,0,0\}$ & $\{0,0,0\}$ & $c_{1}=0$ \\
$x_{4}$ & $\{0,0,1\}$ & $\{0,0,0\}$ & $\{0,1,0\}$ & $c_{1}=2$ \\
\hline
\end{tabular}

for all $e \in A$. The interval-valued fuzzy set $\max _{\mathbb{S}}$ is called the max-threshold of the interval-valued hesitant fuzzy soft set $\mathfrak{S}$. Moreover, the level hesitant fuzzy soft set of the interval-valued hesitant fuzzy soft set $\mathbb{\mathfrak { S }}$ with respect to the max-threshold interval-valued fuzzy set $\max _{\mathfrak{S}}$, namely, $L\left(\mathbb{\Im} ; \max _{\mathfrak{S}}\right)$, is called the top-level hesitant fuzzy soft set of $\mathfrak{S}$ which is simply denoted as $L$ ( $\mathfrak{S}$; $\max )$. In the discussions below, the top-level decision rule means that we will use the max-threshold and consider the top-level hesitant fuzzy soft set in interval-valued hesitant fuzzy soft sets based on decision making.

We also reconsider the interval-valued hesitant fuzzy soft set $\mathbb{S}=(\widetilde{F}, A)$ with its tabular representation shown in Table 1. Table 2 gives the tabular representation of the optimistic reduct interval-valued fuzzy soft set $\left(\widetilde{F}_{+}, A\right)$ of $\mathbb{S}$. From Table 2, the max-threshold $\max _{\mathfrak{S}}$ of $\mathfrak{S}$ can be given as follows:

$$
\max _{\mathfrak{S}}=\left\{\left(e_{1},[0.8,1.0]\right),\left(e_{2},[0.8,0.9]\right),\left(e_{3},[0.8,0.9]\right)\right\},
$$

and the top-level hesitant fuzzy soft set of $\mathfrak{S}$ is a special hesitant fuzzy soft set $L(\widetilde{S}$; $\max )$ with its tabular representation given by Table 6 .

In the following we will present an adjustable approach to interval-valued hesitant fuzzy soft sets based on decision making.

\section{Algorithm 54.}

Step 1. Input an interval-valued hesitant fuzzy soft set $\mathbb{\mathfrak { S } =}$ $(\widetilde{F}, A)$.

Step 2. Input a threshold interval-valued fuzzy set $\lambda: A \rightarrow$ Int $[0,1]$ (or give a threshold value $t \in \operatorname{Int}[0,1]$; or choose the mid-level decision rule; or choose the top-level decision rule) for decision making.

Step 3. Compute the level hesitant fuzzy soft set $L(\widetilde{\Im} ; \lambda)$ of $\mathfrak{S}$ with respect to the threshold interval-valued fuzzy set $\lambda$ (or the $t$-level hesitant fuzzy soft set $L(\widetilde{\Xi} t)$; or the mid-level 


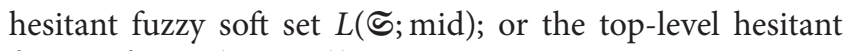
fuzzy soft set $L(\widetilde{\subseteq} ; \max ))$.

Step 4. Present the level hesitant fuzzy soft set $L(\mathbb{S} ; \lambda)$ (or $L(\mathfrak{S} ; t)$; or $L(\mathfrak{S} ; \mathrm{mid})$; or $L(\mathbb{S} ; \max ))$ in tabular form. For any $x_{j} \in U$, compute the choice value $c_{j}$ of $x_{j}$.

Step 5. The optimal decision is to select $x_{k}$ if $c_{k}=\max _{j} c_{j}$.

Step 6. If $k$ has more than one value, then any one of $x_{k}$ may be chosen.

Remark 55. The basic motivation for designing Algorithm 54 is to solve interval-valued hesitant fuzzy soft set based on decision making problem by using level hesitant fuzzy soft sets initiated in this study. By choosing certain thresholds or decision strategies such as the mid-level or the top-level decision rules, we can convert a complex interval-valued hesitant fuzzy soft set into a simple hesitant fuzzy soft set called the level hesitant fuzzy soft set. Thus we need not treat interval-valued hesitant fuzzy soft sets directly in decision making but only deal with the level hesitant fuzzy soft sets derived from them.

To illustrate the basic idea of Algorithm 54, we give the following example.

Example 56. Let us reconsider the decision making problem that involves the interval-valued hesitant fuzzy soft set $\mathbb{S}=$ $(\widetilde{F}, A)$ with tabular representation as in Table 1 . Assume that all the opinions of three judges must be considered by us. So we intend to select the object fulfilling the different standards of three judges in most aspects as the optimal person. Hence, it is reasonable to use the mid-level decision rule for decision making in such cases. In Example 52, we have obtained the mid-level hesitant fuzzy soft set $L(\mathbb{S}$; mid) of $\mathbb{\subseteq}$ with respect to the threshold interval-valued fuzzy set $\operatorname{mid}_{\mathfrak{\subseteq}}$ with its tabular representation given by Table 5 .

In Table 5, we can calculate choice values as follows:

$$
\begin{aligned}
& c_{1}=1+0+0=1, \\
& c_{2}=1+1 \times 3+1 \times 3=7, \\
& \mathcal{c}_{3}=1 \times 2+1 \times 3+1=6, \\
& c_{4}=1 \times 3+1+1 \times 3=7 .
\end{aligned}
$$

From the choice value listed in Table 5, we can conclude that the ranking of the four candidates is $x_{4}=x_{2}>x_{3}>x_{1}$ and the best choice is $x_{4}$ and $x_{2}$.

Next, we use the top-level decision rule to handle the decision making problem. Table 6 gives the tabular representation of the level hesitant fuzzy soft set $L$ ( $\mathfrak{S}$; max) of $\mathbb{S}$. From Table 6, it follows that the ranking of the four candidates is $x_{4}>x_{2}>x_{3}=x_{1}$, and the optimal decision is to select $x_{4}$.

\section{Weighted Interval-Valued Hesitant Fuzzy Soft Set Based on Decision Making}

Section 4 has investigated the application of interval-valued hesitant fuzzy soft sets based on decision making. It is worth noting that the importance of the parameters is not reflected in the process of the above application about intervalvalued hesitant fuzzy soft set. Therefore, the weights of the parameters should be considered by decision makers in many decision making events. Suppose that the parameters that we consider have different weights. In that case, we should take into account the weighted interval-valued hesitant fuzzy soft set based on decision making.

In the present section, inspired by the idea of Feng et al. in $[15,16]$, we first introduce the concept of weighted intervalvalued hesitant fuzzy soft sets and discuss its applications to decision making problems.

Definition 57. Let $(\widetilde{F}, A)$ be the interval-valued hesitant fuzzy soft set over $U$, where $A \subseteq E$ and $E$ is the parameter set. A weighted interval-valued hesitant fuzzy soft set is a triple $\wp=(\widetilde{F}, A, \omega)$ where $\omega: A \rightarrow[0,1]$ is a weight function specifying the weight $\omega_{i}=\omega\left(e_{i}\right)$ for each attribute $e_{i} \in A$.

Remark 58. In Definition 57, if there is only one element in the IVHFE $\widetilde{F}(e)(x)$, we can note that weighted intervalvalued hesitant fuzzy soft sets degenerate into the weighted interval-valued fuzzy soft sets presented by Feng et al. in [16].

Remark 59. When there is only one interval value in the IVHFE $\widetilde{F}(e)(x)$ whose upper and lower limits are identical, it should be noted that weighted interval-valued hesitant fuzzy soft sets in Definition 57 degenerate to the weighted fuzzy soft set introduced by Feng et al. in [15]. In general, the weighted fuzzy soft sets and weighted interval-valued fuzzy soft sets presented by Feng et al. in $[15,16]$ are two special cases of weighted interval-valued hesitant fuzzy soft sets defined by us.

In reality, all the parameters may not be of equal importance in many decision making problems. The importance of different parameters can be described as the weight function in a weighted interval-valued hesitant fuzzy soft set. So the weighted interval-valued hesitant fuzzy soft set can be applied to some decision making problems in which the parameters are not of equal importance.

In order to deal with the weighted interval-valued hesitant fuzzy soft sets based on decision making problems, we develop a revised version of Algorithm 54 by using weighted choice values $\bar{c}_{j}$ as substitutes for choice values $c_{j}$ (see Algorithm 60).

\section{Algorithm 60.}

Step 1. Input a weighted interval-valued hesitant fuzzy soft set $\wp=(\widetilde{F}, A, \omega)$.

Step 2. Input a threshold interval-valued fuzzy set $\lambda: A \rightarrow$ Int $[0,1]$ (or give a threshold value $t \in \operatorname{Int}[0,1]$; or choose 
TABLE 7: Tabular representation of $\mathfrak{G}=(\widetilde{F}, A)$.

\begin{tabular}{llcrl}
\hline$U$ & $e_{1}$ & $e_{2}$ & $e_{3}$ & $e_{4}$ \\
\hline$h_{1}$ & $\{[0.6,0.8],[0.6,0.7]\}$ & $\{[0.6,0.8],[0.6,0.6]\}$ & $\{[0.5,0.6],[0.6,0.7]\}$ & $\{[0.5,0.5],[0.4,0.5]\}$ \\
$h_{2}$ & $\{[0.2,0.3],[0.3,0.5]\}$ & $\{[0.6,0.8],[0.7,0.8]\}$ & $\{[0.7,0.8],[0.5,0.8]\}$ & $\{[0.7,0.7],[0.6,0.9]\}$ \\
$h_{3}$ & $\{[0.5,0.7],[0.6,0.8]\}$ & $\{[0.7,0.9],[0.6,0.8]\}$ & $\{[0.6,0.8],[0.7,0.7]\}$ & $\{[0.8,0.9],[0.9,0.9]\}$ \\
$h_{4}$ & $\{[0.6,0.7],[0.8,0.9]\}$ & $\{[0.5,0.7],[0.7,0.8]\}$ & $\{[0.8,0.9],[0.7,0.8]\}$ & $\{[0.6,0.6],[0.8,0.9]\}$ \\
$h_{5}$ & $\{[0.6,0.8],[0.7,0.9]\}$ & $\{[0.6,0.8],[0.7,0.8]\}$ & $\{[0.6,0.8],[0.4,0.6]\}$ & $\{[0.5,0.7],[0.8,0.8]\}$ \\
\hline
\end{tabular}

TABLE 8: Tabular representation of $\wp=(\widetilde{F}, A, \omega)$.

\begin{tabular}{llcrr}
\hline$U$ & $e_{1}, \omega_{1}=0.4$ & $e_{2}, \omega_{2}=0.2$ & $e_{3}, \omega_{3}=0.15$ & $e_{4}, \omega_{4}=0.25$ \\
\hline$h_{1}$ & $\{[0.6,0.8],[0.6,0.7]\}$ & $\{[0.6,0.8],[0.6,0.6]\}$ & $\{[0.5,0.6],[0.6,0.7]\}$ & $\{[0.5,0.5],[0.4,0.5]\}$ \\
$h_{2}$ & $\{[0.2,0.3],[0.3,0.5]\}$ & $\{[0.6,0.8],[0.7,0.8]\}$ & $\{[0.7,0.8],[0.5,0.8]\}$ & $\{[0.7,0.7],[0.6,0.9]\}$ \\
$h_{3}$ & $\{[0.5,0.7],[0.6,0.8]\}$ & $\{[0.7,0.9],[0.6,0.8]\}$ & $\{[0.6,0.8],[0.7,0.7]\}$ & $\{[0.8,0.9],[0.9,0.9]\}$ \\
$h_{4}$ & $\{[0.6,0.7],[0.8,0.9]\}$ & $\{[0.5,0.7],[0.7,0.8]\}$ & $\{[0.8,0.9],[0.7,0.8]\}$ & $\{[0.6,0.6],[0.8,0.9]\}$ \\
$h_{5}$ & $\{[0.6,0.8],[0.7,0.9]\}$ & $\{[0.6,0.8],[0.7,0.8]\}$ & $\{[0.6,0.8],[0.4,0.6]\}$ & $\{[0.5,0.7],[0.8,0.8]\}$ \\
\hline
\end{tabular}

the mid-level decision rule; or choose the top-level decision rule) for decision making.

Step 3. Compute the level hesitant fuzzy soft set $L((\widetilde{F}, A) ; \lambda)$ of $\wp$ with respect to the threshold interval-valued fuzzy set $\lambda$ (or the $t$-level hesitant fuzzy soft set $L((\widetilde{F}, A) ; t)$; or the mid-level hesitant fuzzy soft set $L((\widetilde{F}, A)$; mid); or the top-level hesitant fuzzy soft set $L((\widetilde{F}, A) ; \max ))$.

Step 4. Present the level hesitant fuzzy soft set $L((\widetilde{F}, A) ; \lambda)$ (or $L((\widetilde{F}, A) ; t)$; or $L((\widetilde{F}, A)$; mid $)$; or $L((\widetilde{F}, A)$; max $))$ in tabular form. For any $x_{j} \in U$, compute the weighted choice value $\bar{c}_{j}$ of $x_{j}$.

Step 5. The optimal decision is to select $x_{k}$ if $\bar{c}_{k}=\max _{j} \bar{c}_{j}$.

Step 6. If $k$ has more than one value, then any one of $x_{k}$ may be chosen.

To illustrate the above idea, we consider the following example.

Example 61. A car company is eager to select the optimum robot for its manufacturing process. Suppose that $U=$ $\left\{h_{1}, h_{2}, h_{3}, h_{4}, h_{5}\right\}$ is a set of five robots and $A$ is a set of four criteria, where $A=\left\{e_{1}, e_{2}, e_{3}, e_{4}\right\}=\{$ load capacity; speed; memory capacity; degree of freedom\}.

Now, assume that two evaluation experts impose the weights on the parameters in $A$ as follows: for the parameter "load capacity," $\omega_{1}=0.4$; for the parameter "speed," $\omega_{2}=$ 0.2 ; for the parameter "memory capacity," $\omega_{3}=0.15$; for the parameter "degree of freedom," $\omega_{4}=0.25$. The two experts evaluate the performances of the alternatives $h_{j}(j=$ $1,2,3,4,5)$ with respect to criteria $e_{i}(i=1,2,3,4)$ and construct an interval-valued hesitant fuzzy soft set $\mathfrak{G}=(\widetilde{F}, A)$ shown in Table 7.

Then the weight function $\omega: A \rightarrow[0,1]$ and the interval-valued hesitant fuzzy soft set $\mathfrak{G}=(\widetilde{F}, A)$ are transformed into a weighted interval-valued hesitant fuzzy soft set $\wp=(\widetilde{F}, A, \omega)$. The tabular representation of $\wp=$ $(\widetilde{F}, A, \omega)$ is shown in Table 8 .
Assume that all the evaluations of two experts for five robots must be taken into account by us. In that case, we should deal with this problem by using mid-level decision rule. That is, we will use the mid-threshold $\operatorname{mid}_{\mathfrak{G}}$. In order to obtain the mid-threshold $\operatorname{mid}_{\mathfrak{G S}}$ of $\mathfrak{G}$, by Definition 25 , we can calculate the neutral reduct interval-valued fuzzy soft set of $\mathfrak{G}$ given in Table 9 . So the mid-threshold $\operatorname{mid}_{\mathfrak{G}}$ of $\mathfrak{G}$ can be obtained as follows:

$$
\begin{array}{r}
\operatorname{mid}_{\mathscr{S}}=\left\{\left(e_{1},[0.55,0.71]\right),\left(e_{2},[0.63,0.78]\right),\right. \\
\left.\left(e_{3},[0.61,0.75]\right),\left(e_{4},[0.66,0.74]\right)\right\} .
\end{array}
$$

By Definition 51, we obtain the mid-level hesitant fuzzy soft set of $\mathfrak{S}$ with respect to the mid-threshold $\operatorname{mid}_{\mathfrak{G}}$. Table 10 gives the tabular representation of the mid-level hesitant fuzzy soft set $L(\mathfrak{G} ; \mathrm{mid})$ with weighted choice values. In Table 10, we can calculate choice values as follows:

$$
\begin{aligned}
& \bar{c}_{1}=0.4 \times 2+0+0+0=0.8, \\
& \bar{c}_{2}=0+0.2 \times 1+0.15 \times 1+0.25 \times 2=0.85, \\
& \bar{c}_{3}=0.4 \times 1+0.2 \times 1+0.15 \times 1+0.25 \times 2=1.25, \\
& \bar{c}_{4}=0.4 \times 2+0.2 \times 1+0.15 \times 2+0.25 \times 1=1.55, \\
& \bar{c}_{5}=0.4 \times 2+0.2 \times 1+0+0.25 \times 1=1.25 .
\end{aligned}
$$

Therefore, according to Table 10, we can conclude that the ranking of the five alternatives is $h_{4}>h_{5}=h_{3}>h_{2}>h_{1}$ and the best choice is $h_{4}$.

As an adjustable approach, one can also use other rules in the above decision making problem and in general the final decision result will change accordingly. For instance, we use the top-level decision rule to handle the decision making problem. Similar to Example 53, Table 11 gives the tabular representation of the level hesitant fuzzy soft set $L(\mathfrak{G} ; \max )$ of $\mathfrak{G}$. From Table 11, it follows that the ranking of the five alternatives is $h_{4}>h_{3}>h_{1}=h_{2}=h_{5}$, and the optimal decision is to select $h_{4}$. 
TABLE 9: NRIVFS of $\mathfrak{G}=(\widetilde{F}, A)$.

\begin{tabular}{lcccc}
\hline$U$ & $e_{1}$ & $e_{2}$ & $e_{3}$ & $e_{4}$ \\
\hline$h_{1}$ & {$[0.60,0.75]$} & {$[0.60,0.70]$} & {$[0.55,0.65]$} & {$[0.45,0.50]$} \\
$h_{2}$ & {$[0.25,0.40]$} & {$[0.65,0.80]$} & {$[0.60,0.80]$} & {$[0.65,0.80]$} \\
$h_{3}$ & {$[0.55,0.75]$} & {$[0.65,0.85]$} & {$[0.65,0.75]$} & {$[0.85,0.90]$} \\
$h_{4}$ & {$[0.70,0.80]$} & {$[0.60,0.75]$} & {$[0.75,0.85]$} & {$[0.70,0.75]$} \\
$h_{5}$ & {$[0.65,0.85]$} & {$[0.65,0.80]$} & {$[0.50,0.70]$} & {$[0.65,0.75]$} \\
\hline
\end{tabular}

TABLE 10: Tabular representation of $L(\mathfrak{G} ;$ mid $)$ with weighted choice values.

\begin{tabular}{cccccc}
\hline$U$ & $e_{1}, \omega_{1}=0.4$ & $e_{2}, \omega_{2}=0.2$ & $e_{3}, \omega_{3}=0.15$ & $e_{4}, \omega_{4}=0.25$ & Weighted choice value $\left(\bar{c}_{j}\right)$ \\
\hline$h_{1}$ & $\{1,1\}$ & $\{0,0\}$ & $\{0,0\}$ & $\{0,0\}$ & $\bar{c}_{1}=0.8$ \\
$h_{2}$ & $\{0,0\}$ & $\{0,1\}$ & $\{1,0\}$ & $\{1,1\}$ & $\bar{c}_{2}=0.85$ \\
$h_{3}$ & $\{0,1\}$ & $\{1,0\}$ & $\{0,1\}$ & $\{1,1\}$ & $\bar{c}_{3}=1.25$ \\
$h_{4}$ & $\{1,1\}$ & $\{0,1\}$ & $\{1,1\}$ & $\{0,1\}$ & $\bar{c}_{4}=1.55$ \\
$h_{5}$ & $\{1,1\}$ & $\{0,1\}$ & $\{0,0\}$ & $\{0,1\}$ & $\bar{c}_{5}=1.25$ \\
\hline
\end{tabular}

TABLE 11: Tabular representation of $L(\mathscr{G} ; \max )$ with weighted choice values.

\begin{tabular}{cccccc}
\hline$U$ & $e_{1}, \omega_{1}=0.4$ & $e_{2}, \omega_{2}=0.2$ & $e_{3}, \omega_{3}=0.15$ & $e_{4}, \omega_{4}=0.25$ & Weighted choice value $\left(\bar{c}_{j}\right)$ \\
\hline$h_{1}$ & $\{0,0\}$ & $\{0,0\}$ & $\{0,0\}$ & $\{0,0\}$ & $\bar{c}_{1}=0$ \\
$h_{2}$ & $\{0,0\}$ & $\{0,0\}$ & $\{0,0\}$ & $\{0,0\}$ & $\bar{c}_{2}=0$ \\
$h_{3}$ & $\{0,0\}$ & $\{1,0\}$ & $\{0,0\}$ & $\{0,1\}$ & $\bar{c}_{3}=0.45$ \\
$h_{4}$ & $\{0,1\}$ & $\{0,0\}$ & $\{1,0\}$ & $\{0,0\}$ & $\bar{c}_{4}=0.55$ \\
$h_{5}$ & $\{0,0\}$ & $\{0,0\}$ & $\{0,0\}$ & $\{0,0\}$ & $\bar{c}_{5}=0$ \\
\hline
\end{tabular}

\section{Conclusion}

In this paper, we propose the concept of interval-valued hesitant fuzzy soft sets and their properties are also investigated. Meanwhile, an adjustable approach to interval-valued hesitant fuzzy soft sets based on decision making is proposed by using level hesitant fuzzy soft sets. Also, we illustrate the efficiency of the novel method by some examples. Moreover, the weighted interval-valued hesitant fuzzy soft set is introduced and an example problem is provided to show the effectiveness of the proposed model. This work can be viewed as the extension of Feng et al. $[15,16]$.

In the future, it is important and interesting to further investigate level hesitant fuzzy soft set approach to decision making based on other extensions of hesitant fuzzy soft set theory, such as dual hesitant fuzzy soft set theory and dual interval-valued fuzzy soft set theory.

\section{Conflict of Interests}

The authors declare that there is no conflict of interests regarding the publication of this paper.

\section{Acknowledgments}

The authors would like to thank the anonymous referees for their valuable comments and suggestions. This work is supported by the National Natural Science Foundation of China (no. 11461082).

\section{References}

[1] D. Molodtsov, "Soft set theory-first results," Computers and Mathematics with Applications, vol. 37, no. 4-5, pp. 19-31, 1999.

[2] H. Aktaş and N. Çağman, "Soft sets and soft groups," Information Sciences, vol. 177, no. 13, pp. 2726-2735, 2007.

[3] D. Molodtsov, The Theory of Soft Sets, URSS Publishers, Moscow, Russia, 2004, (Russian).

[4] P. K. Maji, R. Biswas, and A. R. Roy, "Soft set theory," Computers \& Mathematics with Applications, vol. 45, no. 4-5, pp. 555-562, 2003.

[5] Y. B. Jun, "Soft BCK/BCI-algebras," Computers \& Mathematics with Applications, vol. 56, no. 5, pp. 1408-1413, 2008.

[6] Y. B. Jun and C. H. Park, "Applications of soft sets in ideal theory of BCK/BCI-algebras," Information Sciences, vol. 178, no. 11, pp. 2466-2475, 2008

[7] F. Feng, Y. B. Jun, and X. Z. Zhao, "Soft semirings," Computers \& Mathematics with Applications, vol. 56, no. 10, pp. 2621-2628, 2008.

[8] M. I. Ali, F. Feng, X. Liu, W. K. Min, and M. Shabir, "On some new operations in soft set theory," Computers and Mathematics with Applications, vol. 57, no. 9, pp. 1547-1553, 2009.

[9] K. Qin and Z. Hong, "On soft equality," Journal of Computational and Applied Mathematics, vol. 234, no. 5, pp. 1347-1355, 2010.

[10] X. Yang, T. Y. Lin, J. Yang, Y. Li, and D. Yu, "Combination of interval-valued fuzzy set and soft set," Computers \& Mathematics with Applications, vol. 58, no. 3, pp. 521-527, 2009.

[11] Y. Yang, X. Tan, and C. C. Meng, "The multi-fuzzy soft set and its application in decision making," Applied Mathematical Modelling, vol. 37, no. 7, pp. 4915-4923, 2013. 
[12] P. K. Maji, R. Biswas, and A. R. Roy, "Fuzzy soft sets," Journal of Fuzzy Mathematics, vol. 9, no. 3, pp. 589-602, 2001.

[13] A. R. Roy and P. K. Maji, "A fuzzy soft set theoretic approach to decision making problems," Journal of Computational and Applied Mathematics, vol. 203, no. 2, pp. 412-418, 2007.

[14] Z. Kong, L. Q. Gao, and L. F. Wang, "Comment on 'A fuzzy soft set theoretic approach to decision making problems"' Journal of Computational and Applied Mathematics, vol. 223, no. 2, pp. 540-542, 2009.

[15] F. Feng, Y. B. Jun, X. Liu, and L. Li, "An adjustable approach to fuzzy soft set based decision making," Journal of Computational and Applied Mathematics, vol. 234, no. 1, pp. 10-20, 2010.

[16] F. Feng, Y. M. Li, and V. Leoreanu-Fotea, "Application of level soft sets in decision making based on interval-valued fuzzy soft sets," Computers \& Mathematics with Applications, vol. 60, no. 6, pp. 1756-1767, 2010.

[17] Y. Jiang, Y. Tang, Q. Chen, H. Liu, and J. Tang, "Interval-valued intuitionistic fuzzy soft sets and their properties," Computers \& Mathematics with Applications, vol. 60, no. 3, pp. 906-918, 2010.

[18] Z. Zhang, C. Wang, D. Tian, and K. Li, "A novel approach to interval-valued intuitionistic fuzzy soft set based decision making," Applied Mathematical Modelling, vol. 38, no. 4, pp. 1255-1270, 2014.

[19] Z. Xiao, S. Xia, K. Gong, and D. Li, "The trapezoidal fuzzy soft set and its application in MCDM," Applied Mathematical Modelling, vol. 36, no. 12, pp. 5844-5855, 2012.

[20] H. D. Zhang, L. Shu, and S. L. Liao, "Generalized trapezoidal fuzzy soft set and its application in medical diagnosis," Journal of Applied Mathematics, vol. 2014, Article ID 312069, 12 pages, 2014.

[21] L. A. Zadeh, "Fuzzy sets," Information and Computation, vol. 8, pp. 338-353, 1965.

[22] K. T. Atanassov, "Intuitionistic fuzzy sets," Fuzzy Sets and Systems, vol. 20, no. 1, pp. 87-96, 1986.

[23] M. B. Gorzałczany, "A method of inference in approximate reasoning based on interval-valued fuzzy sets," Fuzzy Sets and Systems, vol. 21, no. 1, pp. 1-17, 1987.

[24] G. Deschrijver and E. E. Kerre, "On the relationship between some extensions of fuzzy set theory," Fuzzy Sets and Systems, vol. 133, no. 2, pp. 227-235, 2003.

[25] G. Deschrijver and E. E. Kerre, "Implicators based on binary aggregation operators in interval-valued fuzzy set theory," Fuzzy Sets and Systems, vol. 153, no. 2, pp. 229-248, 2005.

[26] D. Dubois and H. Prade, Fuzzy Sets and Systems: Theory and Applications, vol. 144 of Mathematics in Science and Engineering, Academic Press, New York, NY, USA, 1980.

[27] S. Miyamoto, "Remarks on basics of fuzzy sets and fuzzy multisets," Fuzzy Sets and Systems, vol. 156, no. 3, pp. 427-431, 2005.

[28] V. Torra and Y. Narukawa, "On hesitant fuzzy sets and decision," in Proceedings of the 18th IEEE International Conference on Fuzzy Systems, pp. 1378-1382, Jeju Island, Republic of Korea, August 2009.

[29] V. Torra, "Hesitant fuzzy sets," International Journal of Intelligent Systems, vol. 25, no. 6, pp. 529-539, 2010.

[30] R. M. Rodriguez, L. Martinez, and F. Herrera, "Hesitant fuzzy linguistic term sets for decision making," IEEE Transactions on Fuzzy Systems, vol. 20, no. 1, pp. 109-119, 2012.

[31] M. Xia and Z. Xu, "Hesitant fuzzy information aggregation in decision making," International Journal of Approximate Reasoning, vol. 52, no. 3, pp. 395-407, 2011.
[32] Z. S. Xu and M. M. Xia, "Distance and similarity measures for hesitant fuzzy sets," Information Sciences, vol. 181, no. 11, pp. 2128-2138, 2011.

[33] D. Dubois and H. Prade, "Rough fuzzy sets and fuzzy rough sets," International Journal of General Systems, vol. 17, pp. 191209, 1990.

[34] X. B. Yang, X. N. Song, Y. S. Qi, and J. Y. Yang, "Constructive and axiomatic approaches to hesitant fuzzy rough set," Soft Computing, vol. 18, no. 6, pp. 1067-1077, 2014.

[35] K. V. Babitha and S. J. John, "Hesitant fuzzy soft sets," Journal of New Results in Science, vol. 3, pp. 98-107, 2013.

[36] F. Q. Wang, X. H. Li, and X. H. Chen, "Hesitant fuzzy soft set and its applications in multicriteria decision making," Journal of Applied Mathematics, vol. 2014, Article ID 643785, 10 pages, 2014.

[37] N. Chen, Z. S. Xu, and M. M. Xia, "Interval-valued hesitant preference relations and their applications to group decision making," Knowledge-Based Systems, vol. 37, pp. 528-540, 2013.

[38] N. Chen, Z. S. Xu, and M. M. Xia, "Correlation coefficients of hesitant fuzzy sets and their applications to clustering analysis," Applied Mathematical Modelling, vol. 37, no. 4, pp. 2197-2211, 2013.

[39] B. Farhadinia, "Information measures for hesitant fuzzy sets and interval-valued hesitant fuzzy sets," Information Sciences, vol. 240, pp. 129-144, 2013.

[40] G. W. Wei, X. F. Zhao, and R. Lin, "Some hesitant intervalvalued fuzzy aggregation operators and their applications to multiple attribute decision making," Knowledge-Based Systems, vol. 46, pp. 43-53, 2013.

[41] H. D. Zhang, L. Shu, and S. L. Liao, "On interval-valued hesitant fuzzy rough approximation operators," Soft Computing, 2014.

[42] Z. S. Xu and Q. L. Da, “The uncertain OWA operator," International Journal of Intelligent Systems, vol. 17, no. 6, pp. 569-575, 2002.

[43] J. Q. Wang, X. E. Li, and X. H. Chen, "Hesitant fuzzy soft sets with application in multicriteria group decision making problems," The Scientific World Journal, vol. 2015, Article ID 806983, 14 pages, 2015. 


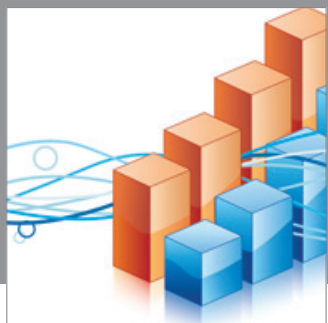

Advances in

Operations Research

mansans

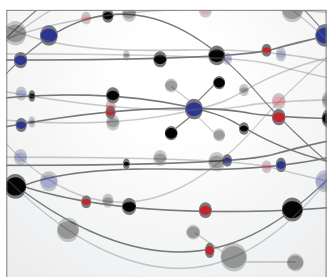

The Scientific World Journal
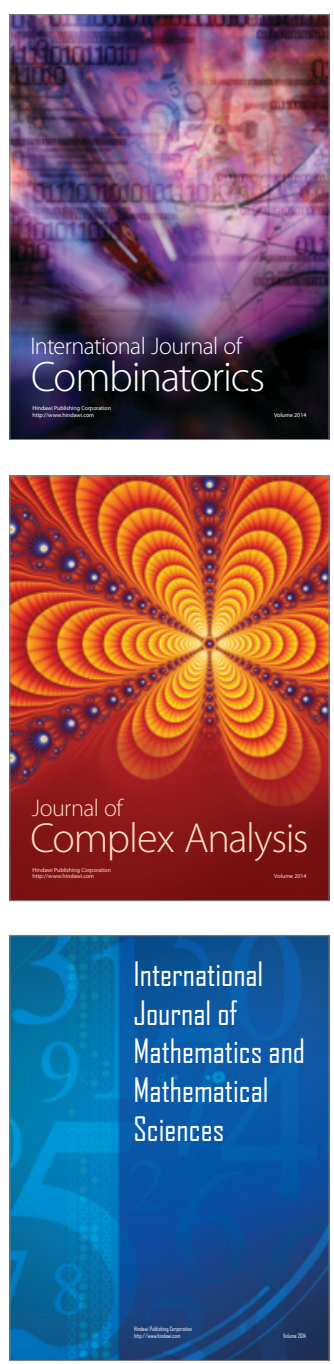
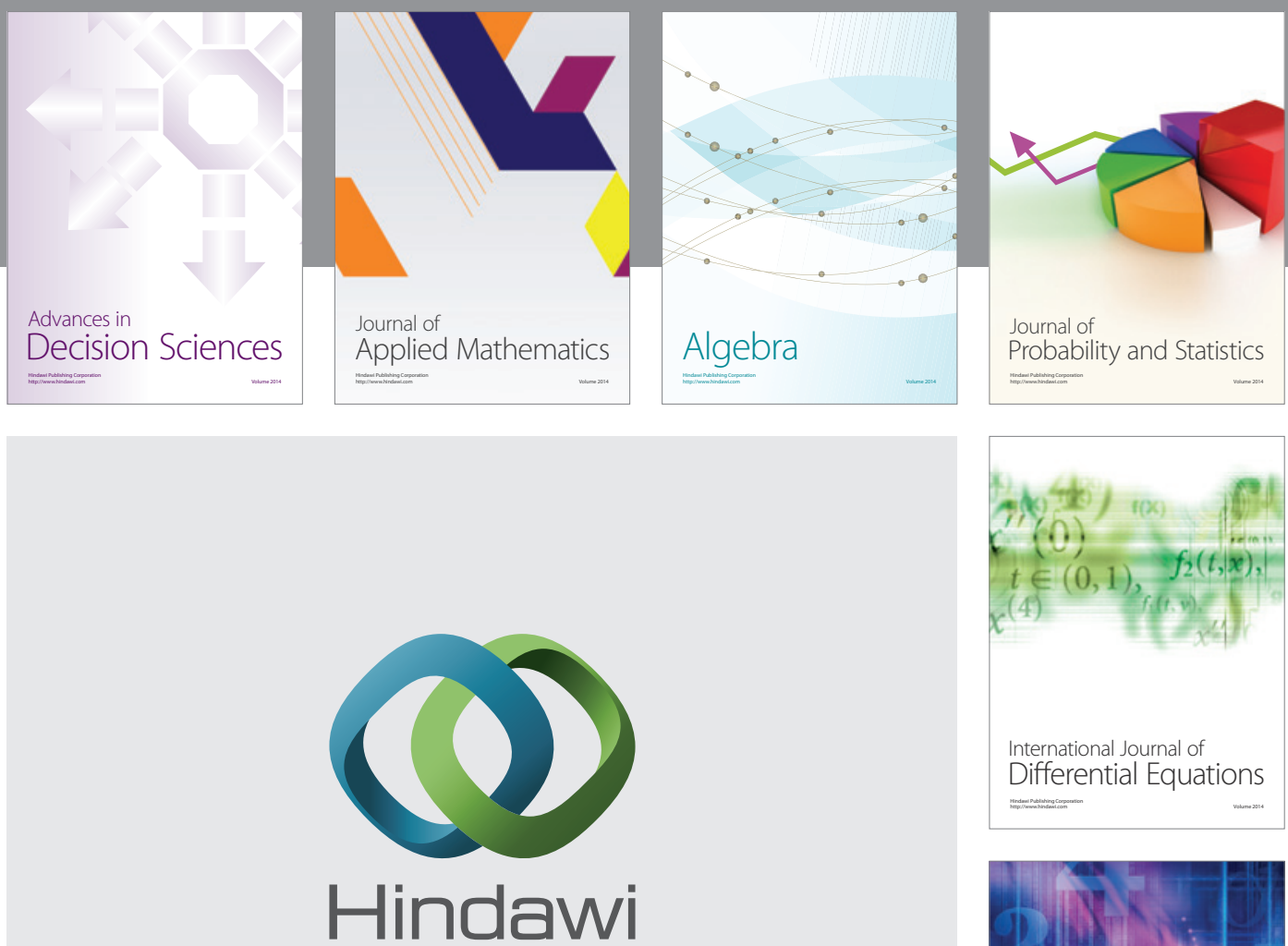

Submit your manuscripts at http://www.hindawi.com
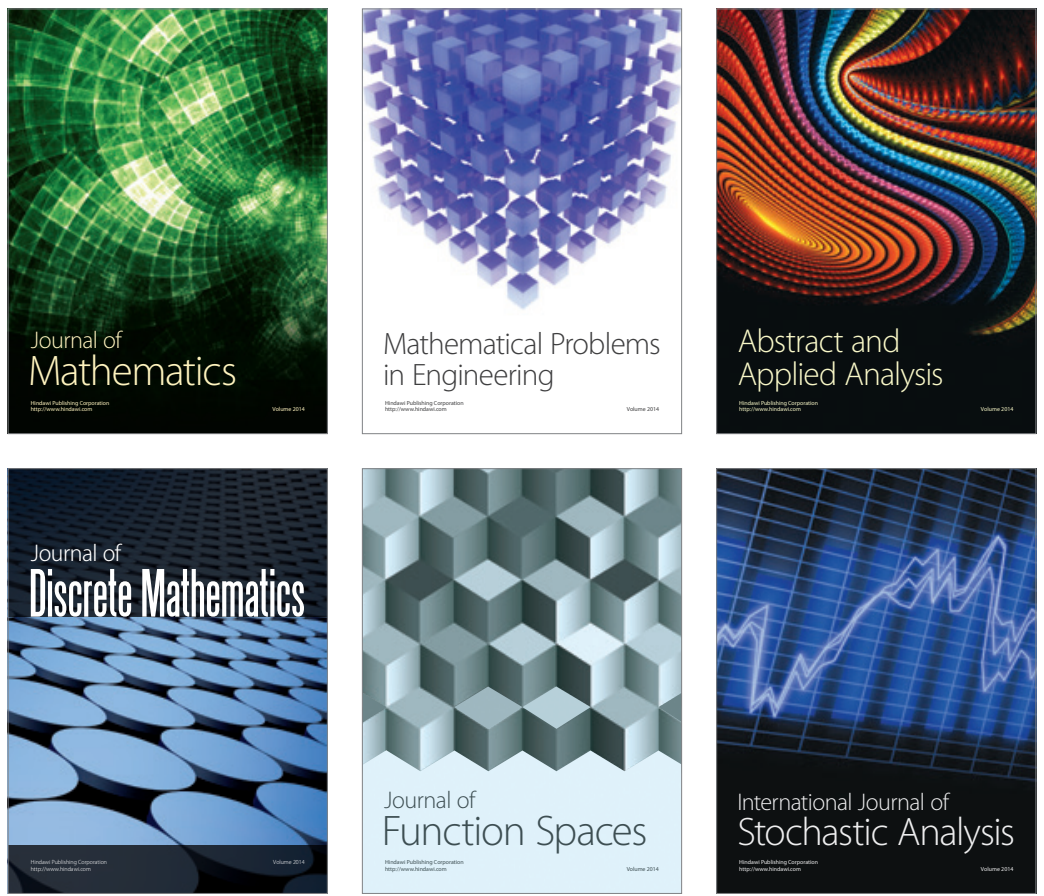

Journal of

Function Spaces

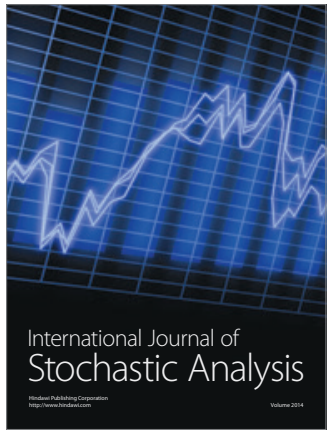

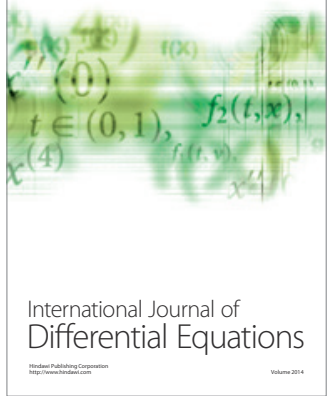
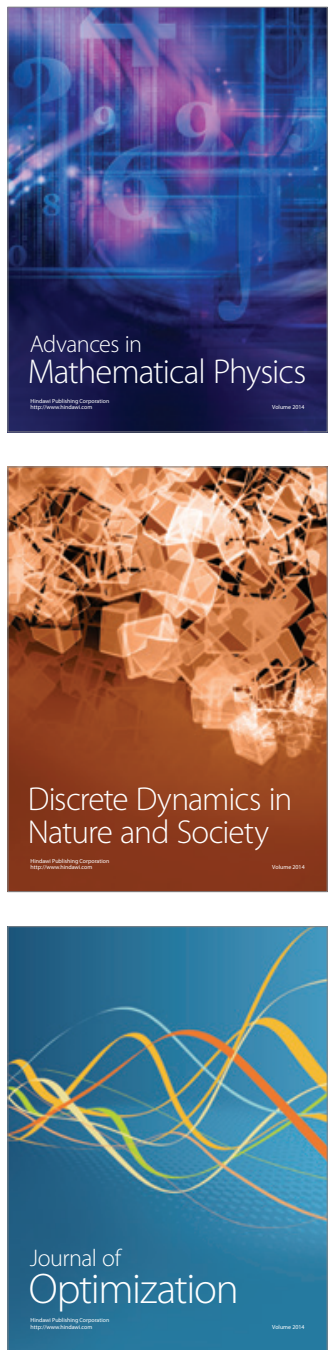